\title{
1994 Fall Meeting Combines Excitement Over Research Advancements with Concern Over Future Direction
}

Excitement over continuing advances in biomimetic materials, the manipulation of nanoscale structures, applications of mathematics to materials problems, and many other research areas mingled with concern over the future funding and direction of materials-related science and engineering at the 1994 MRS Fall Meeting held in Boston from November 28 to December 2.

The meeting sprawled throughout three Boston hotels and featured record-breaking numbers of both papers and participants, with 4,200 papers and posters given and 4,400 researchers in attendance. A wealth of data and insights were conveyed during 34 technical symposia coordinated by meeting chairs Theodore $\mathrm{M}$. Bessman (Oak Ridge National Laboratory), Timothy D. Sands (University of California-Berkeley), and Gary S. Was (University of Michigan).

But meeting highlights also included a cautionary survey of post-Cold War changes in the administration of academic and industrial research from plenary speaker Siegfried Hecker, director of Los Alamos National Laboratory, and a presentation on "industrial ecology"-making manufacturing more compatible with natural ecosystems-from Manufacturing Forum speaker Robert Laudise of AT\&T Bell Laboratories. "With more than 4,000 papers being presented this fall, MRS proves that there is no lack of problems needing to be solved and no shortage of ideas and excitement," Hecker commented during his address (see sidebar, "Hecker, Laudise Address Changing National Role of Materials Research"). But the confluence of the end of the Cold War with other changes-particularly the emergence of a global marketplace and the transition to a "knowledge society" in the U.S.-has created the need for a "new social contract" between government, industry, and academia, Hecker said. Government-supported research must increasingly focus on demonstrable public goods such as environmental protection and sustainable economic growth, he said.

In addition, said Laudise, materials science and engineering needs a heightened "environmental ethic" that aims to cut industrial emissions; turn effluents into

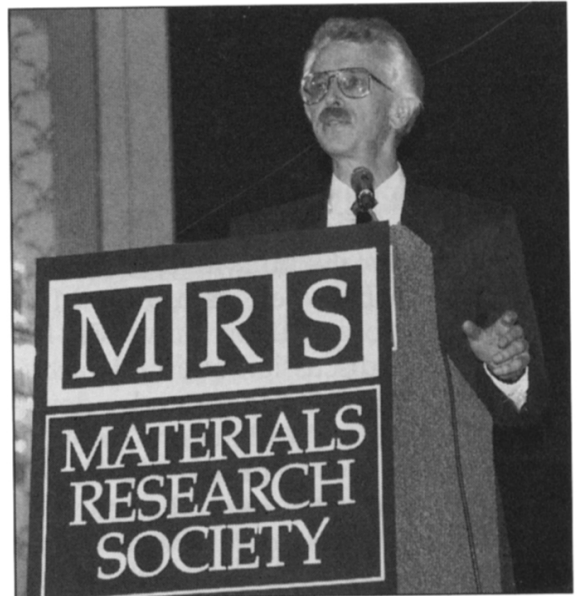

Siegfried Hecker, director of Los Alamos National Laboratory, gives the plenary presentation, "The Cold War is OverWhat Now?"

reusable products; and, in the future, keep track of "where every atom went" in an industrial process. "This is one of the few things you can do that your kids will be proud of you for," Laudise told listeners.

The Society's mission to promote interdisciplinary, goal-oriented research found expression in the dizzying variety of technical work discussed at the meeting. In Symposium Za, Optical Waveguide Materials, E. Ozbay of Iowa State University showed that Lincoln-log-like structures of layered photonic bandgap (PBG) crystals are opaque to electromagnetic radiation over a useful band of frequencies from 100 to $500 \mathrm{GHz}$. Adding or removing dielectric material from each crystal layer creates defects that finely "tune" the frequencies falling into the gaps, Ozbay said. The next generation of such devices, he predicted, will have bandgaps in the optical range, making them useful components in a range of active photonic devices.

Protecting sensitive detecting equipment-including the human eye-from the damaging effects of high-intensity laser light was the focus of a series of presentations during Symposium $\mathbf{Z b}$, Materials for Optical Limiting. James
Shirk of the Naval Research Laboratory (NRL), for example, demonstrated that the molecular structures of organic materials like phthalocyanines assume nonlinear absorption properties when doped with heavy metals. Altered phthalocyanine films become more opaque to laser light at higher energies and longer exposure times, Shirk explained, making them attractive as "fail-safe" protection devices. Shirk's NRL colleague Art Snow later presented measurements of optically clear phthalocyanine glasses synthesized through a combination of hydrogen bonding, stereochemical interactions, and symmetry changes at the periphery of the phthalocyanine rings.

In Symposium W2, Hollow and Solid Spheres and Microspheres, University of Illinois graduate student Mike Wong presented results of recent experiments using ultrasound to create durable, oxygen-rich hemoglobin microbubbles (Figure 1) that may eventually be mass-produced as a substitute for human blood. (See "Awards" description of the MRS Medal Award lecture given by Wong's faculty advisor Kenneth Suslick, who was recog-

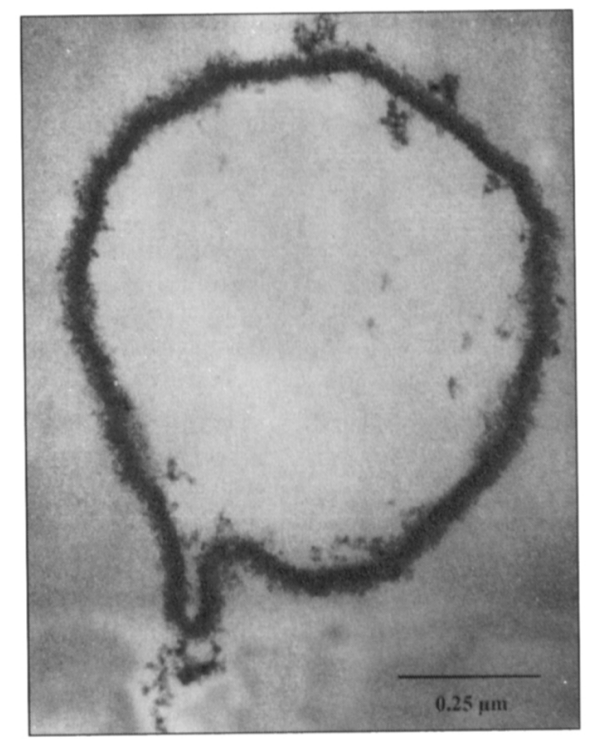

Figure 1. Uitrasound is used to create hemoglobin microbubbles. 


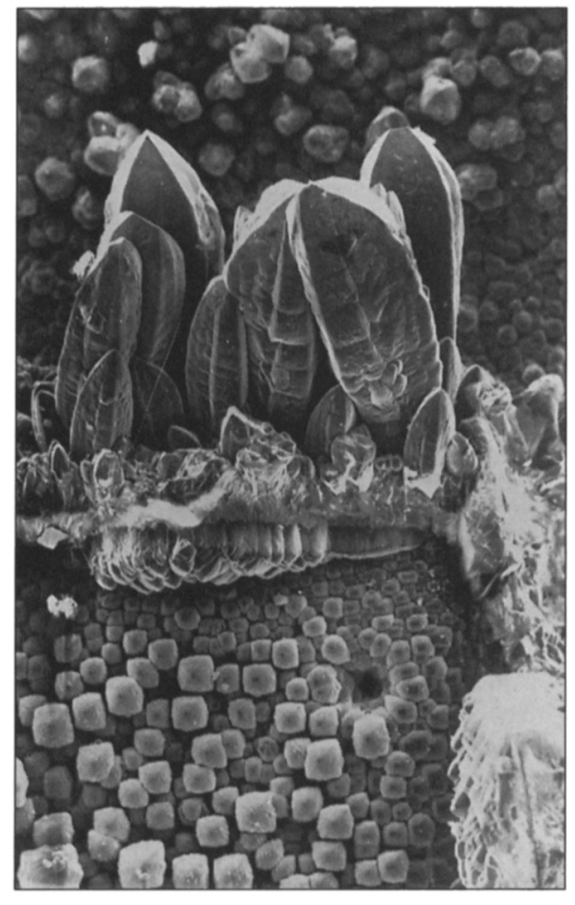

Figure 2. An example of extreme morphological instability during the combustion growth of diamond on a square diamond substrate. The vertical mark on the left-hand side is $100 \mu \mathrm{m}$. Note the unstable, uncontrolled growth of diamond blades on the upper edge of the original square substrate. These bladeshaped crystals grew directly into the direction of the incident flame. Oriented diamond crystals are visible on the flat (100) surface of the diamond substrate. The crystals were grown by Christopher S. Kovach, Case Western Reserve University, Cleveland, Ohio. The scanning micrograph was taken by Tetsuya Suzuki of Toshiba Tungaloy Co. Kawasaki, Japan.

nized for his pioneering work in the field of sonochemistry.) The tiny spheres form when ultrasound-induced bubbles in a hemoglobin solution collapse, creating hot spots that foster chemical welding of the hemoglobin molecules into bubbles about half the size of natural red blood cells. Though the material has not yet been tested in animal or human bloodstreams, Wong's measurements show that the microbubbles carry 50 percent more oxygen than the same volume of real blood.

John Angus of Case Western Reserve University reported his group's findings on morphological instability in diamond growth during Symposium K, Chemical Vapor Deposition of Refractory Metals and Ceramics III. Angus showed striking electron photomicrographs (see Figure 2) of the blade-shaped diamond crystals that can grow atop a cubic diamond substrate when the atomic hydrogen-hydrocarbon ratio in the combustion flame fluctuates. Achieving stable growth of synthetic diamonds by vapor deposition will require an active means of damping these fluctuations, perhaps by enhancing diffusion on the crystal surface, Angus said.

Marvin Cohen of the University of California-Berkeley kicked off Symposium Oa, Computational Approaches and Applications to Predicting Properties of Complex Materials, with a survey of potential superhard compounds identified using a "standard model" formula relating a crystal's bulk modulus to the bond length between its atoms. M.A. Keegan of George Mason University followed with a discussion of an interactive electron-structure database under development at NRL in Washington. The database will list crystal properties, energy bands, density states, and other parameters for the entire periodic table as well as for a variety of hydrides, carbides, nitrides, oxides, and other compounds, and will soon be available for free dial-up access, Keegan said.

Other symposia covered atomic-level control of epitaxial heterostructures, microcrystalline and nanocrystalline semiconductors, ferroelectric thin films, applications of synchrotron radiation techniques to materials science, and an abundance of other topics. See the symposia summaries on the following pages for highlights. More detailed information will be available in the published proceedings.

\section{Defining Biomimetics Research}

In a special panel-discussion session of Symposium S, Biomolecular and Biomimetic Materials, researchers lamented the ambiguity of the very term "biomimetics" and attempted to reach consensus on a new descriptor for the field's central concerns and goals. "When I got started in this field eight years ago I wasn't even sure what biomimetics was, and I'm still not sure," said panel organizer Joe Cesarano of Sandia National Laboratories. Cesarano distributed a survey form asking attendees to state their own definitions of the materials or processes currently described as "biomimetic" and to assess whether the current understanding is adequate for the needs of the scientific and industrial communities. The form also asked whether respondents believed that composites and ceramics modeled on skin, muscle, bone, teeth, or shells will have commercial usefulness within 20 years.
Panelist Rustum Roy of Pennsylvania State University said that the term "biomimetic" exaggerates the field's true potential and said scientists who use the term to promote their research invite an eventual backlash from funding agencies. Since the root word "mimesis" connotes "resemblance in external form," Roy pointed out, only materials whose structures are based directly on biological models should be called biomimetic. Roy proposed "biognosis" as a more accurate term describing the application of knowledge derived from biology to materials science.

Other panelists took issue with Roy's etymological conservatism. Mark Alper of the University of California-Berkeley said the issue was "purely semantic" and unrelated to the science itself. Nonetheless, Alper said he preferred the term "biomolecular" to describe research on materials that are (a) made by a living organism, (b) made by a living organism and then modified in a laboratory, (c) made by organisms that have themselves been modified, or (d) made in vitro by a process patterned after an organic one.

\section{Manufacturing Forum}

Speakers at the Fall forum on materials issues in manufacturing included Robert Laudise of AT\&T Bell Laboratories (see sidebar, "Hecker, Laudise Address Changing National Role of Materials Research") and John Hopps, director of the Division of Materials Research at the National Science Foundation (NSF) and chief of photonics technology at Draper Laboratories in Cambridge, Massachusetts. Hopps previewed a joint NSFDepartment of Energy workshop on "Materials for the Clean Car" scheduled for January 1995 in New Orleans. Hopps said the workshop would address six issues critical to the future construction of energy-efficient, environmentally friendly vehicles, including materials and processes for energy storage and energy conversion, lightweight materials, emissions control, the impact of emissions on the atmosphere, and advanced sensors for control, performance, and emissions.

Hopps said the workshop's findings will be compatible with the work of the ongoing government-industry "Partnership for a New Generation of Vehicles," but added that "we are looking at issues that will be important to industry long beyond the development and testing of the [Partnership's] prototype," planned for 2002. Interest in new vehicle technologies has been building for many years at NSF, Hopps said, and funds from other NSF programs are already being redirected to increase support for clean-car research. 


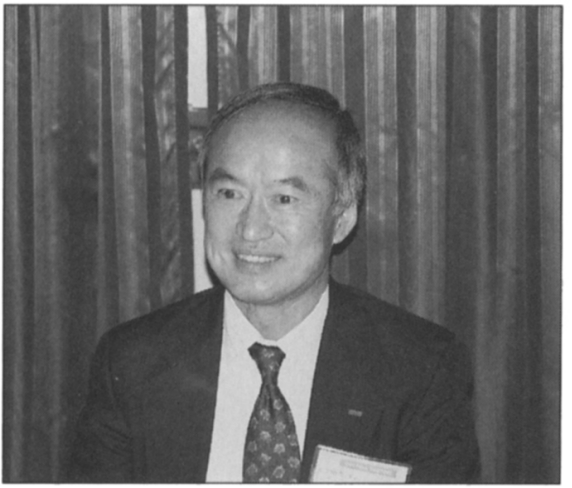

Alfred Y. Cho, director of AT\&T Bell Laboratories' Semiconductor Research Laboratory and recipient of the 1994 Von Hippel Award.

\section{Awards}

Headlining the Society's November 30 awards ceremony was the presentation of the 1994 Von Hippel Award to Alfred Y. Cho, director of AT\&T Bell Laboratories Semiconductor Research Laboratory, for his pioneering work in the development of the molecular beam epitaxy (MBE) crystal growth process. Cho's award lecture reviewed major milestones in MBE science and technology, from his own work in the early 1970 s on in situ monitoring of gallium arsenide semiconductor crystal growth all the way to the recent construction of indium-gallium-arsenide "staircas-

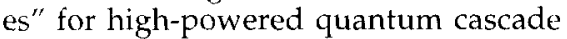
unipolar semiconductor lasers. Though other means of fabricating atomic monolayer films have emerged, Cho said, MBE "will continue to lead in crystal growth for precision, uniformity, and reproducibility." The awards ceremony also honored the 13 recipients of MRS Graduate Student Awards, chosen from a list of 140 nominations and 30 finalists (see sidebar), and welcomed to the Society two new student chapters at Columbia University and the University of Washington.

MRS Medals recognizing recent major achievements in materials-related fields went to Max Lagally of the University of Wisconsin-Madison and Kenneth Suslick of the University of Illinois at UrbanaChampaign. Lagally presented his medal lecture, "Strange and Wonderful TwoDimensional Structures in Epitaxial Growth," as part of Symposium B1, Evolution of Thin-Film and Surface Structure and Morphology. Lagally described recent measurements explaining why quasifractal silicon crystal growth occurs atop triangular lattices but not square lattices. He also discussed the use of scanning tunnel-

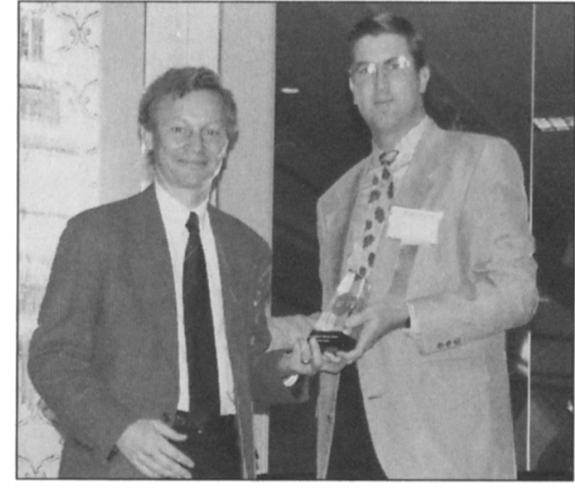

Max Legally (left) of the University of Wisconsin-Madison receives one of the MRS Medals from 1994 MRS President John Bravman.

ing microscopy to carry out "atomic scale lithography," the creation of monolayer islands or bridges for future nanoscale electronic circuits.

Suslick's medal lecture, "Ultrasound
Applications to Materials," explained how cavitation, or the formation, growth, and implosive collapse of bubbles in liquids exposed to high-frequency sound, creates "hot spots" that allow chemical reactions to proceed in previously inaccessible regimes of duration, energy, and pressure. One application of this technique, Suslick showed, is in the creation of metal samples that freeze into amorphous structures before crystal growth can occur. Amorphous iron produced in this way has such a large surface area that it burns spontaneously on contact with air; such materials, Suslick said, may have very useful catalytic and superparamagnetic properties.

The Turnbull Lectureship-recognizing the career of a scientist who has made outstanding contributions to understanding materials phenomena and properties through research, writing, and lecturing, as exemplified by namesake David Turnbull-was given at this year's Fall Meeting by Arthur Nowick of Columbia University. Nowick spoke on "The Golden Age of Crystal Defects" (see sidebar).

\section{Graduate Student Awards Presented at the 1994 MRS Fall Meeting}

MRS presented 13 Graduate Student Awards at the 1994 Fall Meeting in Boston. The awards are intended to honor and encourage graduate students whose academic achievements and current materials research display a high order of excellence and distinction.

Each award consists of a $\$ 250$ cash prize, payment of the registration fee for the meeting, and a presentation plaque.

For information on upcoming deadlines for Graduate Student Awards applications, contact Anne Wagner, Materials Research Society, 9800 McKnight Road, Pittsburgh, PA 15237-6006; tel. 412-367-3003; fax 412-367-4373.

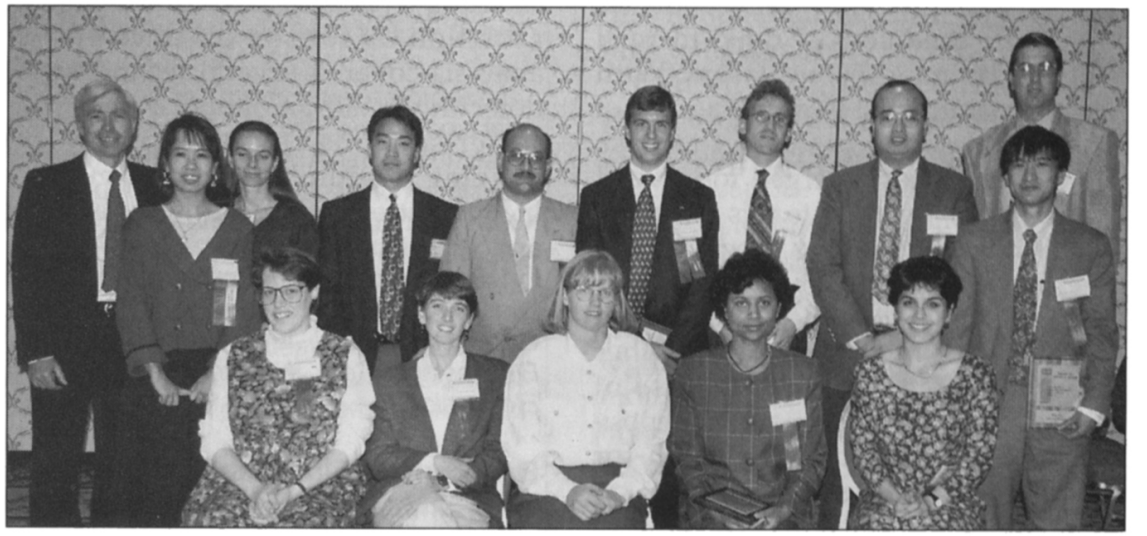

Graduate Student Award Recipients at the 1994 MRS Fall Meeting.

(Seated left to right) Elaine Kleinfeld, Rachel Goldman, Kristi Anseth, Rina Chowdhury, and Deidre Olynick.

(Standing left to right) Tom Picraux, 1993 MRS President, Sue Feng, Nicola Hill, Daniel Lee, Maher Amer, Boris Vuchic, Uwe Hessinger, Mike Wong, Wu Li, and John Bravman, 1994 MRS President. 
New Developments Arise in Energetic Beam Synthesis and Characterization (See MRS Proceedings Volume 354)

Symposium A, Beam-Solid Interactions for Materials Synthesis, continuing the extensive coverage of this topic in previous Fall Meetings, held sessions on ionbeam-assisted deposition, ion implantation, ion beam mixing, and ion-beaminduced hardening. New control of sputtered microstructures was demonstrated as the result of an improved basic understanding of the mechanisms involved, resulting in the production of superior devices. Also highlighted was the growing area of ion-irradiation-induced property modification in polymer materials. Certain model polymer systems can be made harder than some steels by using single- and multiple-species ion beams. In characterization, new developments in the use of focused ion beams for increased spatial resolution of grain structure and in the use of low-energy beams for hydrogen and deuterium analysis were presented.

The symposium emphasized the significant role that laser radiation plays both in the characterization of solids, thin films, and surfaces and in the modification and synthesis of new materials. Regarding characterization, sessions encompassed key advances such as progress in surface analysis by means of nonlinear optical methods and the application of resonance ionization spectroscopy to elemental analysis of solids. Many papers examined applications of laser radiation to material modification and synthesis. Advances were reported, for example, in understanding the limits to the epitaxial growth of semiconductor alloys under conditions of rapid thermal annealing by nanosecond lasers. With respect to nonthermal laser processing of surfaces, a detailed picture of surface photochemistry has emerged for several model systems. Coupled to this increased level of understanding has been a further refinement in the applications of lasers for precise control in the formation of semiconductor microstructures. Other presentations centered on the use of pulsed laser ablation for material deposition, now the standard approach for preparing several types of thin films.

A session was devoted to new advances in materials characterization in transmission (TEM) and scanning transmission electron microscopes (STEM). The analyses of semiconductor materials using electron energy loss spectroscopy (EELS) and atomic number contrast microscopy were covered in multiple presentations. The ability to image the presence and strength

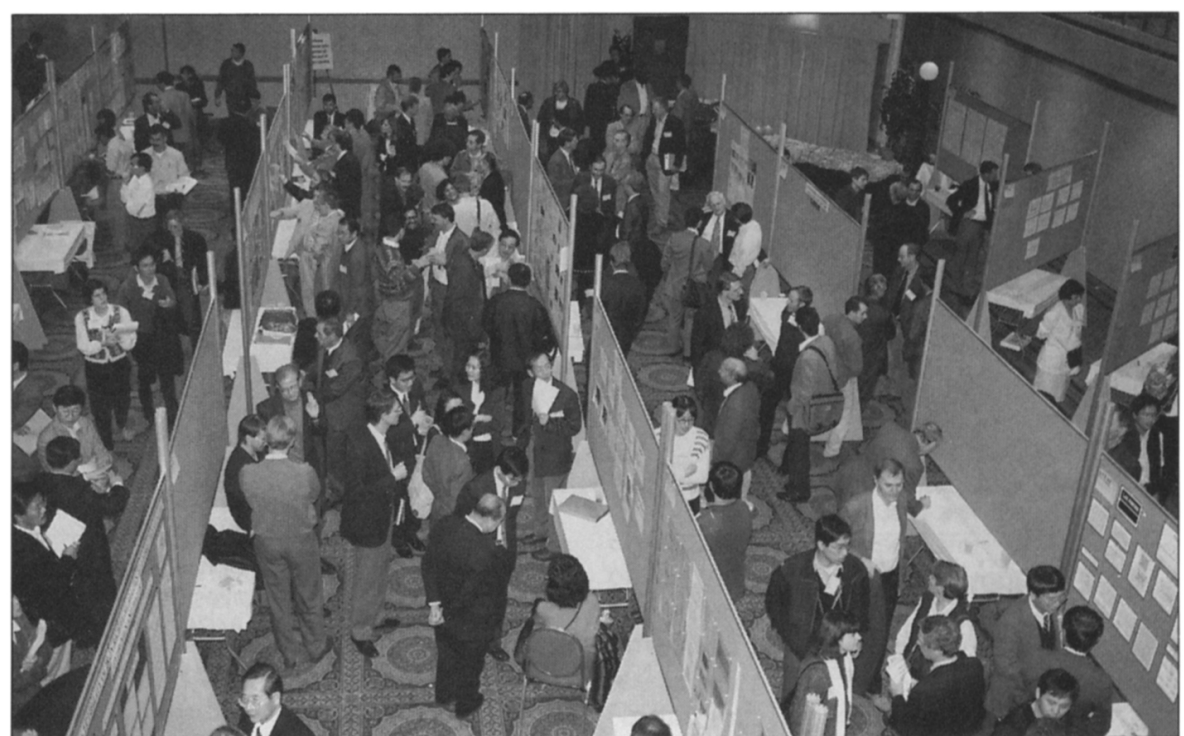

A record-breaking number of 4,200 papers and posters were presented at the 1994 MRS Meeting in Boston.

of magnetic and electric fields in the microscope using electron beam holography was also presented. Several new developments in high-resolution TEM included an improved understanding of the sources of noise in images of lattice structures and the use of complementary atomistic simulation analysis of materials to enable the solution of complex structures in metals and alloys.

The analysis of material composition was a common theme. Presentations were made on composition imaging and analysis using ions, $x$-rays, electrons, and laser radiation. A session on trace element analysis covered several techniques for detecting small amounts of impurities. Other sessions covered composition imaging of multilayer thin films using incoherent elastic scattering of electrons and $x$-ray fluorescence.

Symposium Support: Anatech Ltd., Coherent Laser Group, Eaton Corp., Fisons Instruments, Genus Inc., Hitachi, JEOL USA Inc., National Electrostatics Corp., Nanotec Corp., Philips Electronic

\section{Researchers Elucidate Techniques for Examining Surface Structure and Morphology \\ (See MRS Proceedings Volume 355)}

Symposium B1, Evolution of Thin-Film and Surface Structure and Morphology, was a week-long examination of the applications of various techniques for examining surface structure and morphology in a wide variety of materials.
The emphasis was on the type of information attainable rather than materials specific. U. Diebold (Tulane Univ.) and D. Bonnell (Univ. of PA) described novel methods of characterizing the electronic state and initial (cluster) growth scenarios of metals on metal oxide substrates. H.A. Atwater (CIT) discussed the use of energetic beams to produce heretofore thermodynamically metastable alloys. R.M. Feenstra (IBM) detailed the development of surface morphology (monitored by AFM) in terms of strain relief via the formation of facets and misfit dislocation arrays. R.M. Tromp (IBM) continued this theme, showing both in situ (low-energy electron microscopy) and ex situ (TEM) strain relaxation via (edge) dislocation injection. J. Ozcomert (Univ. of MD) provided dynamic studies of step fluctuations, using STM. T. Gustafsson (Rutgers Univ.) outlined surface structural studies applying high-resolution RBS.

A variety of novel surface techniques were presented, as well. J.M. Gibson (Univ, of IL) described the measurement of surface stress and L.M. Marks (Northwestern Univ.), the determination of surface structure in ultra-high-vacuum TEMs. S.M. Chiang (U.C.-Davis) and M.S. Altman (Hong Kong Univ.) presented spin-polarized LEEM investigations designed to correlate surface topography with magnetic domain structures. K. Babcock (Digital Instruments) covered the state of the art of magnetic force microscopy for describing the same. 


\section{Nowick Recalls "Golden Age" of Crystal-Defect Research}

"Scientists don't pay enough attention to history"--so began Columbia University researcher Arthur Nowick, deliverer of the 1994 MRS Turnbull Lecture. Nowick's talk, entitled "The Golden Age of Crystal Defects," recounted the decade of research advances starting in 1949 that, Nowick said, raised the study of crystal defects from a level of rudimentary and crude concepts to a relatively mature field of study. Nowick, who received his PhD degree that same year, said he wanted to use his talk to "illustrate how a young scientist was influenced by the exciting things going on around him."

Though the theory of dislocations in crystal surfaces had its roots in research completed in the 1920s and 1930s, Nowick said, it was not until after World War II that a quantitative understanding of crystal defects began to develop, noting senior leaders such as F. Seitz, N.F. Mott, W. Shockley, and C. Zener.

Dislocations at first were just an interesting mathematical theory that fit what was already observed in plastic deformation, Nowick said. Then Nowick's own doctoral thesis showed that the nonlinear, stress-sensitive loss of mechanical energy in a crystal under increasing strain amplitude was independent of the strain frequency. This phenomena-dislocation dampingcould only be explained by the theory of dislocations. The observed hysteresis meant that dislocations held by pinning points broke away.

Nowick recounted the excitement at a 1950 conference, the Pittsburgh Symposium on Plastic Deformation, where Frank and Read, after chatting about how a whole slip band can be generated, came up with their idea of dislocation generators and presented it the next day as an unscheduled paper.

There followed a burst of scientific activity on dislocations that culminated in the 1956 Lake Placid conference on dislocations and mechanical properties of crystals. By this time, direct observation of dislocations had been achieved using etch pits, decoration methods, and transmission electron microscopy, Nowick said.

Nowick described conceptual developments surrounding crystal point defects, which again had their origin in the 1920s and 1930s with the concepts of Frenkel and Schottky defects. Huntington and Seitz had calculated in 1942 that self-diffusion energy on the surfaces of closepacked metals like copper could be demonstrated to be much lower if a vacancy mechanism rather than a direct atomic interchange mechanism, was at work. In 1950. Zener added the possibility of a "ring mechanism" to the picture.

A widely talked about phenomena was the Kirkendall effect, involving diffusion experiments in bimetallic systems with markers. The most well-known paper was by Smigelskas and Kirkendall in 1947, Nowick said. In a Cu/Zn/Cu couple, it was found that $\mathrm{Zn}$ diffuses out faster than $\mathrm{Cu}$ diffuses in, which was explained by the presence and motion of defects. One initial skeptic, Mehl, and his student, da Silva, did careful experiments in 1951 which confirmed and expanded on the previous findings, thus putting the effect on a firm foundation, Nowick said

Quenching from high temperatures and annealing was another way of demonstrating the presence of defects. It was possible to monitor annealing out of vacancies from the quenched material by following the relaxation time of the zener (anelastic) relaxation phenomenon, where variations of a factor of 1000 were observed. This gave direct evidence for the presence of defects as well as the separate determination of the formation energy and the migration energy for defects.

Differential dilatometry could also be used to confirm the presence of point defects. A macroscopic volume change that differed from the change due to lattice parameter expansion could be attributed to vacancies or interstitials. Experiments by Nowick with Ralph Feder in 1958 confirmed this effect in aluminum. The measuring techniques were further refined first by Balluffi and Simmons, and then by Feder.

During the later 1950s, work began to focus on the effects of radiation damage on crystals Bombardment by the high energy particles created primarily Frenkel defects, kicking atoms into interstitial sites. John Brinkman and others with him at the North American Aviation Company (now Rockwell), irradiated materials at liquid nitrogen temperatures, and then watched stages of annealing. Then a group at GE (Corbett and Walker in 1959) went to liquid helium temperatures and found five substages of defect annealing attributed to Frenkel pairs at different distances, discovering that $70 \%$ of the damage as seen by electrical resistivity annealed out below liquid nitrogen temperatures.

Fred Seitz led much of the study of alkali halides, and then the concept of association of defects (e.g., cation and crystal vacancy) was developed, for example, by the work of Lidiard in 1956. Association also led to dielectric relaxation due to charged dipoles, as well as to rapid impurity diffusion and other effects.

Kröger and Vink then studied more practical and complex materials, said Nowick, bringing together atomic and electronic defects, for instance, in II-VI compounds. They showed that the concentration of defects is a function of the partial pressure of one of the components and developed a new notation that took into account the effective charge of the defects.

It is interesting to note that much of the basic work on crystal defect of this period took place at industrial laboratories like AT\&T, General Electric, Phillips, Sylvania, U.S. Steel, and North American Aviation, Nowick said.

"I feel very fortunate to have emerged at the start of this Golden Age," Nowick concluded. He added, however, that "every age has its opportunities...you just need to look carefully," and he wished the many researchers in the standing-room-only audience success in finding opportunities like the ones he found.
Finally, the expanding field of surface roughness investigation was addressed by J. Schneir (NIST) and P.E. Russell (NC State Univ.), who discussed critical factors involved in quantification by scanning probe techniques, and by K.W. EvansLutterodt (AT\&T) who surveyed the range of applicability of scanning probe versus $x$-ray scattering techniques for the measurement of surface roughness.

Symposium Support: DC Assoc., Denton Vacuum Inc., Digital Instruments Inc., Evans East, Gatan Inc., JEOL USA Inc., Intel Corp. Park Scientific Instruments, Physical Electronics.

\section{Measurement Techniques and Mechanical Properties of Thin Films Investigated \\ (See MRS Proceedings Volume 356)}

The fifth in a series of symposia entitled Thin Films: Stresses and Mechanical Properties, Symposium B2, comprised more than 185 papers.

The unique mechanical properties of thin films have spurred continuing interest in the development of techniques for thin-film measurement. A substantial number of presentations emphasized specialized techniques for measuring thin films and stresses in thin films. Particularly interesting with respect to the latter were the presentations of optical spectroscopic methods for determining stresses in extremely small volumes. Among measurement techniques, depth-sensing submicron indentation, or nanoindentation, continues to dominate, with some 25 papers presented in this area alone. Important developments include ever more quantitative analyses for complicated samples and the presentation of the first nanoindentation results obtained at high temperatures.

Continuing growth was seen in the areas of fracture, adhesion, and wear. Particularly promising are the applications of various surface force microscopy methods to investigate the microscopic mechanisms of wear processes.

A number of papers addressed heteroepitaxial thin films, which are technologically important in the semiconductor industry, and provide a fertile ground for investigations of fundamental phenomena. Strain relief and dislocation mechanics, diffusion and phase transformations, and evolution of surface topography due to stresses in such films were described.

The ways in which stresses develop in thin films was addressed through detailed investigations into the origins of stresses for particular film materials. Decisive relationships between film deposition parameters and the resulting microstructure, 
and between the microstructure and stresses and mechanical properties were elucidated.

Multilayered thin films were discussed in terms of mechanical strength, stiffness, and the development of stresses. Not surprisingly, interfaces play a significant role in all three areas. The mechanical behavior of a range of alloy systems for use as conducting metallizations in integrated circuits were discussed. Finally, the special properties of polymeric thin films were illustrated.

Symposium Support: Advanced Micro Devices, Dow Chemical, Komag Inc., Tencor instruments.

\section{Progress Seen in the Structure Control of Epitaxial Heterostructures}

Considerable progress has been made in controlling the structure of epitaxial heterostructures. Symposium D, AtomicLevel Control of Epitaxial Heterostructures, focused on several conditions limiting the production of perfect structures.

First, in strained systems, the lattice mismatch between the substrate and overlayer eventually leads to the formation of dislocations. D. Jesson et al. (ORNL) spoke about highly strained systems and the formation of surface cusps. These sites lead to stress concentration and act as nucleation centers for the formation of dislocations. A. Cullis (Defense, Malvern) spoke about in situ $x$-ray studies of low-strain systems in which the native dislocation density in the substrate plays the initial critical role. This study pointed to a two-stage process that involves first the bending over of pre-existing threading dislocations, then the activation of new sources.
A second theme to emerge was the role of statistical roughening and the importance of a diffusion barrier at step edges. G. Ehrlich (Univ. of IL) used field ion microscopy to directly observe atomic motion on terraces and near step edges. He found that atoms do indeed have a reduced probability to cross steps; he also determined that atoms are likely to sit close to the edge of a step. From this microscopic data, several authors showed how the large-scale surface morphology would be impacted. J. Stroscio (NIST) showed STM images of Fe homoepitaxy, and the development of mounds as the overlayer thickened. These ideas were reinforced and amplified in a theoretical model by D.D. Vvdensky (Imperial College).

Symposium Support: Air Products \& Chemicals inc., DCA, Digital instruments, EPI, Fisons Instruments Inc., MCP Wafer Technology Inc., MDC Vacuum Products Inc., Morton International, Omicron Assoc., RHK Technology; Thermionics Lab. Inc.

\section{New Directions in the Chemistry of Electronic Materials Flourish}

Symposium E, Chemical Perspectives of Microelectronic Materials, spanned a range of new directions in the chemistry of electronic materials. Novel methods for patterning or deposition of materials and for in situ monitoring of materials processing were highlighted. Very fine dimensional control over growth using focused laser beams, controlled use of surface chemistry, and photochemistry were demonstrated. In situ probing of surface species and topography during film growth using IR spectroscopy, as well as TEM and AFM microscopies, revealed new details of growth mechanisms. Despite decades of work in $\mathrm{Si}$ chemistry, this area continues to thrive. Polycarbosilanes and polysilanes are attracting new interest as all-dry-processing resist materials.

One session dealt with several developments in copper CVD that have improved the reliability of the process, especially when using $\mathrm{Cu}(\mathrm{hfac})$ (tmvs). Use of the direct liquid injection method has allowed more complicated CVD precursor "formulations" that improve the stability of the precursor during storage (accomplished by adding excess tmvs) and the smoothness of the $\mathrm{Cu}$ films (accomplished by adding Hhfac $2 \mathrm{H}_{2} \mathrm{O}$ ). Further developments in the deposition of gold, aluminum, tungsten, and titanium nitride rounded out this session.

Another session provided details on the alkylsilanes and germanes among the more promising alternatives to silane and germane for the deposition of silicon and germanium. Thin-film and bulk samples of $\mathrm{Bi}_{2} \mathrm{Te}_{3}$ and $\mathrm{Sb}_{2} \mathrm{Te}_{3}$ were prepared by reacting bis-(trimethylsilyl)tellurium with the tris-(dimethylamido)stibane and bismuthane complexes. Transition metal systems such as NiTe were readily synthesized using zerovalent metal complexes and $\mathrm{PR}_{3} \mathrm{Te}$. In several cases novel cluster intermediates were isolated. Finally, new single-source precursors were reported for the growth of thin films of $\mathrm{ZnS}, \mathrm{GaN}$, $\mathrm{SiC}$, and transition-metal gallides.

In one of the most exciting sessions of the symposium, the latest developments in nanocrystalline CdSe were described. M.G. Bawendi (MIT) and coworkers were able to drastically reduce the polydispersity of the nanocrystals. The narrow size distribution allowed the detailed assignment of the optical transitions within the clusters and allowed the nanocrystals to pack in well-ordered two- and threedimensional arrays. A somewhat different approach produced a molecular crystal containing individual cluster units of $\mathrm{Cd}_{17} \mathrm{~S}_{4}(\mathrm{SR})_{26}$. The cluster units were connected into a three-dimensional $\mathrm{ZnS}$-like network through bridging SR ligands.

Si etching in halogen-containing plasmas remains an area of active research Low-pressure plasmas with high charge densities and low ion energies have emerged as the optimum conditions for the fine-line etching required today. Several papers dealt with experimental and theoretical aspects of this topic. Experimental observations and model predictions are beginning to converge.

A joint session with Symposium I1, Materials for Smart Systems, focused on the rapidly expanding area of chemical 
sensors. Choice of the appropriate chemically selective interface materials was shown to be key in implementing surface acoustic wave devices - transducers with thin-film sensing elements that can be sensitive to, for example, $0.5 \%$ of a monolayer of carbon atoms. A novel sensor approach for the detection of semiconductor process gases such as ammonia, phosphine, and arsine utilized the change

\section{Hecker, Laudise Address \\ Changing National Role of Materials Research}

Uncertainty over the place of government- and industry-supported materials research in a time of swift economic and geopolitical change and burgeoning environmental awareness animated two major presentations at the MRS Fall Meeting. In a plenary lecture entitled "The Cold War Is Over-Now What?", Los Alamos National Laboratory director Siegfried Hecker described the shifting rationale for government spending on materials-related research and proposed a new three-pronged mission for Department of Energy (DOE) laboratories in which the agency's old focus on defense is replaced by fundamental science, research to reduce the danger from nuclear weapons, and technology for sustainable development. The next day, Manufacturing Forum speaker Robert Laudise of AT\&T Bell Laboratories called on materials researchers to help bring about sharp reductions in the pollution and inelficiency that occur at each stage of the "materials cycle" from extraction to consumption.

Hecker structured his speech as a series of questions posed by a mock audience member. To the question "is the chaos in academia and industry really that profound, or does it just reflect the end of the Cold War?" Hecker answered yes, then no. The skyrocketing costs of research and the diminished threat from nuclear foes mean that research support from the Federal government must be supplemented by "strategic alliances" between universities and industry, but global competition means that industrial corporations are less willing than ever to support long-term research. High-tech corporations like AT\&T and IBM, meanwhile, are learning to integrate $R \& D$ with product design and marketing more effectively, but with the result that the old, scientifically productive system of "commercial national laboratories" is decaying.

Yet at the same time, Hecker said, materials research has achieved an unprecedented level of productivity. He singled out atomic-force microscopy and nanoscale structures, applications of modeling, simulation, and large-scale computation to materials problems, and biomolecular and biomimetic systems as particularly exciting areas of research. So why can't the peace dividend be applied to this new class of problems? Hecker asked. Because the peace dividend is peace, not dollars, he responded. The defense R\&D budget has declined and the civilian R\&D budget has not picked up the slack. In addition, civilian initiatives such as economic competitiveness do not enjoy the consensus to replace defense as an organizing theme for government research. The industry's need for proprietary rights to new industrial processes is inconsistent with the public's right to benefit freely from tax-supported research.

The most likely theme for future federal support of R\&D, Hecker said, will be developing technologies that allow economic growth and protect the natural environment at the same time. While the term "sustainable development" might be a passing fad, he said, the underlying concepts will survive. In this context, Hecker concluded, the role of Los Alamos and other DOEsupported national labs (including their materials research divisions) concentrated in three areas: (1) continued defense responsibilities including stewardship of the enduring nuclear weapons stockpile; stabilizing, storing, and disposing of military and commercial plutonium; and helping to stem the spread of nuclear weapons; (2) development of technologies for clean energy, and pollution prevention and remediation; and (3) basic research with a focus on interdisciplinary research and large user research facilities. These missions will allow the laboratories to develop next-generation capabilities such as advanced computing to serve the broader national interest in partnership with universities and industry.

Robert Laudise focused his Manufacturing Forum remarks on what he called "green materials and green processes." The government response to the revolution in environmental awareness in the 1960s-laws aimed at "regulation and remediation"-has become overly burdensome and needs replacing, Laudise said. The emerging concept of "industrial ecology" rejects the old understanding of the environment as an endless sink for emissions and effluents in favor of industrial designs that are part of, and synergistic with, natural ecosystems. Such designs incorporate recycling, use environmentally benign processes and products, and minimize waste and byproducts, Laudise said. As it becomes a source of competitive advantage he asserted, good industrial ecology pays for itself.

Laudise cited automobile recycling, telecommuting, and the elimination of lead and chlorofluorocarbons as examples of advances in industrial ecology made possible by materials research. The new commandments for ecologically aware materials scientists and engineers he said, include minimizing carcinogenic content, minimizing emissions, turning effluents into products, eliminating poisons, and tracking the fate of "every atom" in an industrial process. Companies can undertake these strategies at no extra cost by building on the existing knowledge base about green processes, Laudise concluded-"and if they don't try, the environmental laws will do it for them."

in photoluminescence intensity resulting from the modification of surface band structure following adsorption of these gases on a CdSe substrate. A common theme in this session was the necessity to understand the materials chemistry associated with sensor response.

Symposium Suppont: Hughes Aircraft Co. IBM T.J. Watson Research Center, NSF, ONR, Schumacher.

\section{Advances in Nanocrystalline and Microcrystalline Semiconductors Range from Molecular Clusters to Polycrystalline Thin Films (See MRS Proceedings Volume 358)}

Symposium F, Microcrystalline and Nanocrystalline Semiconductors, was the third in a series of MRS Fall symposia devoted to the preparation, characterization, and theory of semiconductor micro/ nanostructures whose properties are influenced by size effects. This symposium brought together materials scientists and engineers, condense matter physicists, physical and electrochemists, and electrical engineers to share their recent advances in four materials fields: semiconductor nanocrystals, porous silicon, nano/micro- and polycrystalline films, and single-crystal quantum structures (including dots, wires, and wells).

One scientific theme unifying all these fields is the modification of the properties of semiconductors that results from electronic confinement. The common challenge, however, is to understand (and often to minimize) the influence of surfaces, interfaces, grain boundaries, and intergranular phases on the properties of nano/microcrystalline semiconductors. In many materials systems, porous silicon being a classic example, discerning intrinsic effects of electron confinement from the extrinsic effects of surfaces is difficult. The common technological application among the nano/microcrystalline semiconductors relies on the unique optical properties, including efficient visible photoluminescence that persists at room temperature. As a result, electroluminescent devices with a wide variety of designs are being developed and optimized.

Materials advances described in the symposium involve structures ranging from $<1 \mathrm{~nm}$ to $1 \mu \mathrm{m}$ in size. At the smallest end of the scale $(<1 \mathrm{~nm})$, a detailed description of the predicted properties of $\mathrm{Si}_{46}$ molecular clusters was presented (S. Saito, Tokyo Inst. of Technology). On a larger scale $(1.5-10 \mathrm{~nm})$, the preparation of CdSe nanocrystallites has been refined to yield a remarkably narrow size distribution $(\sigma<5 \%)$. Hence, the discrete electronic transitions that result from electron con- 
finement within the quantum dots were clearly revealed (M. Bawendi, MIT). Several new methods for preparing quantum dot structures from Si also emerged. These structures provide a better understanding of the luminescent properties of porous silicon, which are unclear due to the complex structure of the material. In fact, it has been suggested that visible luminescence in porous silicon originates from nanocrystals of dimensions $<1.5 \mathrm{~nm}$ (P. Citrin, AT\&T). The most mature field covered, that of nano/micro- and polycrystalline thin films, continues to advance. New techniques to control the nucleation of these films have evolved, using the layer-by-layer technique of alternating cycles of growth and atomic $\mathrm{H}$ etching (G. Parsons, NC State Univ.; I. Shimizu, Tokyo Inst. of Technology). This approach has important applications in the fabrication of higher performance thin-film transistors.

Symposium Support: Asahi Glass Co. Ltd., AT\&T, Canon Inc., Daimler-Benz Corp. Research Labs., Fuji Electric Co. Ltd., Hitachi Ltd., Kaneka Corp., Kawasaki Steel Corp., Kyocera Corp.-Shiga Plant, Mitsui Toatsu Chemicals inc., Sanyo Electric Co. Ltd., Sharp Corp.-Energy Conversion Labs., Siemens Research Labs., Sony Corp., Xerox Palo Alto Research Center.

\section{Applications Sought for Fullerenes and Novel Carbon Materials}

\section{(See MRS Proceedings Volume 359)}

Symposium G, Science and Technology of Fullerene Materials, encompassed both experimental and theoretical results of the ongoing efforts to create, characterize, and find applications for fullerenes and related novel carbon materials. The diversity of conditions leading to fullerene formation was demonstrated by reports showing practical flame production of fullerenes, that a solar furnace can make fullerenes, and that fullerenes are prominent in certain regions of ordinary candle flames.

Similarly, production of carbon nanotubes was reported not only in cathode deposits but also in flame soots, pyrolysis products of hydrocarbons (with and without metal catalysts present), soot produced by laser vaporization of graphite, and in arc fullerene generators with added metal catalysts. Other nanotube papers focused on purification and on field emission from tube tips as a factor controlling the arc plasma during growth and as a potentially useful phenomenon enabling fabrication of novel cold-cathode field emitters.

Encapsulation of crystalline materials including boron carbide and high-blocking-temperature magnetic alloys in closed polyhedral particles with graphitic walls was discussed. Fullerene-like particles and tubules based on noncarbon layer compounds such as $\mathrm{BN}$ and $\mathrm{MoS}_{2}$ and its analogues were reported. A session on endohedral fullerenes featured talks on isolation of reasonably large $(10 \mathrm{mg})$ quantities of individual isomers of metal-atom-containing species and their characterization by a wide variety of techniques, and on the application of ${ }^{3} \mathrm{He} \mathrm{NMR}$ to follow the chemistry of He-containing fullerenes. Theoretical efforts to understand the structural properties of fullerenes, nested fullerenes, and nanotubes were reported. One prediction was that crystallization of single-layer nanotubes may give anomalously rigid low-density structures.

Several sessions focused on fullerenes as condensed-phase films and solids. Trends in the occurrence of superconductivity in alkali- $\mathrm{C}_{60}$ compounds were summarized, and evidence for superconductivity at 40 $\mathrm{K}$ in pressure-stabilized $\mathrm{C}_{3} \mathrm{C}_{60}$ was reported. A study of $\mathrm{Rb}$-doped $\mathrm{C}_{70}$ compounds found no superconductivity, so $C_{60}$ salts remain the only fullerene superconductors. Considerable interest arose in $C_{60}$ solids and films and their photoconductivity, epitaxial growth, optical properties, behavior at high photoexcitation levels, and photochemistry-particularly photopolymerization and photodimerization.

Perhaps the strongest advances toward applications of fullerenes were in the burgeoning areas of fullerene chemistry, functionalization, and polymerization. A sample of a star-polymer consisting of $C_{60}$ molecules linked three-dimensionally by poly(urethane-ether) chains was passed through the audience during a talk discussing the novel elastomer. A wide variety of chemical derivatives of both $C_{60}$ and $C_{70}$ were described, and such potential pharmaceutical applications as HIV protease inhibitors or biological radical scavengers were suggested for some derivatives.

Symposium Support: Air Force Office of Scientific Research, China Technical Consultants Inc., Digital Instruments, Exxon Research and Engineering Co., Hoecht AG, lgol lle De France, NEC Corp., ONR, Pica, President Enterprises, Rhone-Poulenc, Strem Chemicals, Techno-Carbo, Texas Center for Superconductivity, Tokyo Instruments Inc., Toray Research Center Inc

\section{Developments Demonstrated in High $\mathbf{T}_{\mathrm{c}}$ Superconductivity}

In Symposium H, High $T_{c}$ Superconductivity-Materials and Applications, three areas in particular had noteworthy results: novel materials, junctions, and BSCCO wires and tapes.

In the area of novel materials, the infinite layer compounds reported on by $\mathrm{R}$. Feenstra (ORNL), and M. Kawai (Inst. of
Physical and Chemical Research), and the closely related oxycarbonate-substituted materials described by B. Raveau (Lab. CRISMAT) and Y. Matsui (NIRIM) evolved from curiosities to materials worthy of serious consideration. The infinitelayer materials, because of their structural simplicity, have the potential to provide key insights into the nature of HTS. Carbonates, normally a curse to HTS, have been shown to be potentially beneficial to the development of high $T_{c}$ and high $J_{\mathrm{c}}$ materials. $\left(\mathrm{Cu}_{0.5} \mathrm{Cu}_{0.5}\right) \mathrm{Ba}_{2} \mathrm{Ca}_{3} \mathrm{Cu}_{4} \mathrm{O}_{11}$ has demonstrated $T_{c}$ to $117 \mathrm{~K}$ and magnetization $J_{c}$ in zero field above $10 \mathrm{~A} / \mathrm{cm}^{2}$ at $5 \mathrm{~K}$ and above $10^{6} \mathrm{~A} / \mathrm{cm}^{2}$ at $77 \mathrm{~K}$.

Considerable progress has been demonstrated in the development of HTS, SNS, and SIS junctions. One key has been the use of Co-substituted YBCO as the metallic layer in an SNS junction such as that reported by B.D. Hunt (Jet Propulsion Lab., CA). These junctions are starting to look more classical. Use of junctions between $\mathrm{YBCO}$ and conventional superconductors (R.C. Dynes, U.C.-San Diego, Y. Gim, Univ. of MD), have been used to probe the nature of the superconductivity in cuprates. The results indicate that this superconductivity may not be classic BCS s-wave, but may not be exclusively d-wave either.

Work in the BSCCO wires continues to progress. L.J. Masur (American Superconductor Corp.) demonstrated $1 \mathrm{~km}$ multifilament conductors with properties approaching those for shorter lengths. How active the core is in the superconducting transport remains a major question. Recent magnetooptic imaging results reveal that the majority of the supercurrent flows in the skin of the HTS filaments (A. Pashitski, Univ. of WI).

Symposium Support: Conductus Inc. Neocera Inc

\section{Symposium Highlights Applications of Materials for Smart Systems} (See MRS Proceedings Volume 360)

The symposium on Materials for Smart Systems, I1, revolved primarily around the use of ferroelectrics, magnostrictors, and shape memory materials in the design of compact sensors and actuators. Productive joint sessions were also held in the areas of ferroelectric film-based transducers and chemical sensors.

In the ferroelectrics sessions, innovative work on new antiferroelectric-based actuator compositions, SAW-based actuators, and ferroelectric composites was presented. In addition, fundamental studies on the behavior of well-established piezoelectric compositions under severe mechanical or electrical drive conditions were discussed. 
Several speakers highlighted the incorporation of ferroelectric actuators into commercial products, including gyroscopes, actively damped automobile suspensions, and medical diagnostic equipment.

The session on magnetostrictive materials and applications began with an invited talk by A. Clark (Clark Assoc.) on highpower magnetostrictive materials, namely, the rare-earth and rare-earth-iron alloys that exhibit large strains from cyrogenic temperatures to $250^{\circ} \mathrm{C}$. I. Hahn (JPL) reported on a new low-temperature valve using a rare-earth alloy which is operational and leak-tight to temperatures as low as $2.2 \mathrm{~K}$ (superfluid He temperatures)! Talks on the rare-earth-iron alloys, especially terfenol-D, ranged from development of devices to characterization techuiques and growth of single crystals. Other papers focused on the amorphous iron-based magnetostrictive materials, magnetomechanical sensors, and magnetostrictive damping. $\mathrm{H}$. Savage (BCS Inc.) proposed an innovative accelerometer requiring no pickup coils, which uses the Giant Magneto-Impedance Effect as the detection method.

One full day of the symposium was devoted to recent developments in shape memory alloys (SMAs). An overview of SMA fundamentals was given by $\mathrm{K}$. Otsuka (Univ. of Tsukuba), followed by sessions on fundamentals and thin films, high-temperature and Cu-based SMAs, alloying effects and transformation in NiAl- and NiTi-based SMAs, and applications of SMAs. T.W. Deurig (Nitinol Device and Components) in a well-attended talk, surveyed the present and future applications of SMA and superelastic materials, and highlighted the increasing use of these materials, especially in the medical field.

A recurring theme was the use of solidstate sensors and actuators in systems for space applications. Interesting talks describing this were given on the corrective optics for the Hubble telescope, landbased telescopes which correct for atmospheric distortions in the images, and chemical sensors for exploration of the Martian soil.

Symposium Support: Army Research Office, ORNL, ONR

\section{Major Advances Seen in \\ Ferroelectric Thin Films}

(See MRS Proceedings Volume 361)

This fourth symposium in a series, Ferroelectric Thin Films IV, Symposium I2, highlighted the continuing rapid progress in this area, particularly over the past two to three years. Joint sessions were organized with Symposium I1

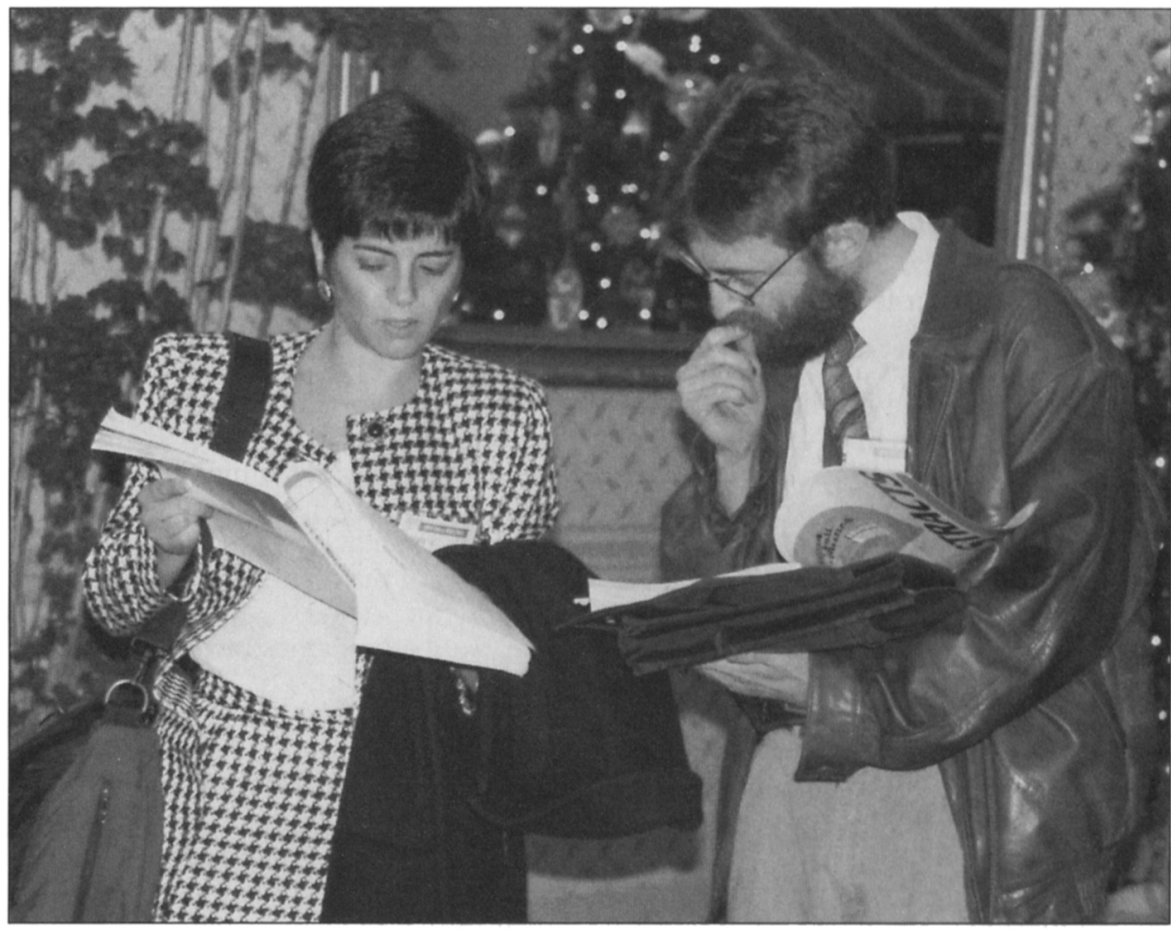

Conference attendees compare notes

(Smart Materials) and Symposium C (Interface Properties), consistent with the interdisciplinary nature of these fields. Three topics in this symposium were especially noteworthy.

The first was the advances being made in understanding the reliability of ferroelectric thin films, relevant to both the nonvolatile and volatile modes of operation. The effects of deposition and processing conditions were discussed in several presentations, and highlighted in invited talks by $\mathrm{O}$. Auciello et al. (Center for Microelectronics), A. Grill (IBM), D. Vijay (Virginia Polytechnic Inst. and State Univ.), and J. Lee (Bellcore). A. Kingon (NC State Univ.) presented a comprehensive overview of the various materials issues germane to the integration of ferroelectric perovskites with Si-CMOS. The effect of electronic and ionic defects were detailed by several speakers, led by W.L. Warren's (Sandia National Labs.) invited lecture on the degradation mechanisms in thin-film ferroelectrics.

Another important feature of this symposium was the revelation of the structure, composition, and some of the processing details of the heretofore undisclosed materials popularly known as "Y1." "Y1" has been known for some time to be a layered perovskite, and this was confirmed by the presentation of $\mathrm{M}$.
Huffman (Symetrix), discussing the processing details of " $Y 1$." Other talks also discussed the deposition of thin films of these layered ferroelectrics by PLD.

On another front, progress is clearly being made on CVD techniques for the growth of ferroelectric thin films. $M$. Shimizu and T. Shiosaki (Kyoto Univ.), outlined the progress being made in this area. Other talks outlined the major issues that still need to be addressed, including compositional stoichiometry in multicomponent systems, delivery systems for precursors, and microstructure-processingelectrical property correlations.

Symposium Support: Neocera inc., Northern Telecom Electronics, Sandia National Labs.

\section{HalJ-Petch Relationship Further Validated for Fine-Grained Materials} (See MRS Proceedings Volume 362)

Symposium Jb, Grain Size and Mechanical Properties-Fundamentals and Applications, was dedicated to the pioneering work of N.J. Petch of Strathclyde Univ. Two invited guest speakers devoted major portions of the early sessions to elaborating on Petch's contributions, which have been instrumental in the understanding of the role of grain size in mechanical properties of polycrystalline materials. His early formulation, which relates the strength of polycrystalline 
materials to the inverse square root of the grain size, has now been expanded to explain the mechanical properties of a host of materials ceramics, intermetallic compounds, and cementitious and other materials. The Hall-Petch relationship is now considered to be a most useful concept in the field of materials science, with foundation both in terms of theory and experiment.

One major attempt in this symposium was directed to the application of the Hall-Petch relationship in the area of ultrafine grains and nanocrystalline materials. Both ultrafine and nanocrystalline materials apparently obey this relationship; however, additional experimental work is required to define the lower limit of the grain size where the relationship holds unambiguously. Most specifically, the application of the Hall-Petch relationship must be investigated in the case of clusters formed at the early stages of crystallization from the glassy state of the rapidly solidified alloys.

Many papers described the Hall-Petch relationship in terms of dislocation mechanics in the polycrystalline alloys subjected to the tensile, compressional, fatigue, and creep experiments. All of these papers provided solid evidence for the validity of the Hall-Petch relationship and supported the notion that further attempts ought to be made to find the relationship in almost all classes of materials having finite particulates, regardless of whether their compositions are metallic or nonmetallic in nature.

Symposium Support: ITAC Ltd., ONR.

\section{Debate Ensues Regarding High-Temperature Ordered Intermetallic Alloys}

(See MRS Proceedings Volume 364)

The sixth biennial symposium on HighTemperature Ordered Intermetallic Alloys, Symposium L, covered a wide variety of material systems, including $\mathrm{Ni}$-, $\mathrm{Fe}-, \mathrm{Ti}$ - and $\mathrm{Nb}$-aluminides; $\mathrm{Al}_{3} \mathrm{Ti}$-based trialuminides; $\mathrm{Ti}_{2} \mathrm{AlNb}$-based "orthorhombic" alloys; Mo-, $\mathrm{Cr}$-, and $\mathrm{Nb}$-silicides; and Laves phases. Two parallel sessions were held to accommodate roughly 170 oral presentations.

Micromechanical behavior continued to be a prominent theme, particularly the characterization and modeling of dislocations in $\mathrm{Ni}-, \mathrm{Ti}^{-}$, and Fe-aluminides and the relationship of dislocation character to strain rate, temperature, and other conditions. Research activity dealing with atomistic modeling of dislocation cores and fine-scale electron microscopy of dislocations appears to be increasing for $\mathrm{TiAl}$ alloy. Researchers reached consider- able agreement on specific observations and measurements of micromechanical behavior, but the synthesis of the observations into a cohesive explanation of macroscopic thermomechanical behavior was an area of much debate for all of the aluminide intermetallics.

Commercial applications for intermetallics continue to be elusive. Cost appears to be the Achilles' heel, and several speakers stressed that more research must be devoted to low-cost processing methods for making parts from intermetallics. Titanium aluminide automobile engine valves represent the largest market that intermetallics are poised to enter, and several auto companies have been investigating cast $\alpha_{2}+\gamma$ alloys for this purpose. Auto companies have concentrated on lowering manufacturing cost by developing a reusable mold-casting method requiring no hot isostatic pressing step.

Intermetallic matrix composites were discussed for a wide variety of systems. Two different classes of composites were treated: hard-phase reinforced materials for improved creep properties and ductile-phase reinforced materials for improved toughness. Hard-phase reinforced systems getting significant attention included $\mathrm{NiAl}+\mathrm{SiC}, \mathrm{Al}_{2} \mathrm{O}_{3}, \mathrm{TiC}$, or $\mathrm{Y}_{2} \mathrm{O}_{3} ; \mathrm{Ni} \mathrm{Nil}_{3} / \mathrm{TiC} ; \mathrm{TiAl} / \mathrm{Al}_{2} \mathrm{O}_{3} ;$ and $\mathrm{MoSi}_{2} / \mathrm{SiC}$. Most attention in the ductilephase reinforced systems focused on $\mathrm{NiAl} / \mathrm{Fe}, \mathrm{MoSi}_{2} / \mathrm{Nb}, \mathrm{Nb}_{5} \mathrm{Si}_{3} / \mathrm{Nb}$, and $\mathrm{Cr}_{3} \mathrm{Si} / \mathrm{Cr}$.

Environmental effects, especially moisture-induced hydrogen embrittlement, and oxidation behavior were discussed for a large number of material systems. The influence of ternary alloying additions and reinforcing phases on oxidation properties was of particular interest.

Symposium Support: Ishikawaiima-Harima Heavy Industries Co. Ltd., Mitsubishi Materials Corp., Mitsui Engineering and Shipbuilding Co. Ltd., NASA Lewis Research Center, Nippon Steel Corp., ORNL, ONR, and RIMCOF.

\section{Benefits of Ceramic Matrix Composites Reported}

\section{(See MRS Proceedings Volume 365)}

The excellent attendance at more than 100 papers presented in Symposium M, Ceramic Matrix Composites: Advanced High-Temperature Structural Materials, demonstrated the continued interest in and importance of ceramic matrix composites. The opening presentation described the benefits of utilizing continuous fiber-reinforced ceramic matrix composites in industrial and power generation applications. Inserting these materials in only a fraction of the available systems is projected to result in significant reductions in cost, energy, and pollution.

The symposium opened with papers on constituents, fibers, and matrices, followed by composite processing, modeling of mechanical behavior, and thermomechanical testing. More stable reinforcements are necessary to enhance the performance and life of fiber-reinforced ceramic composites and to ensure final acceptance of these materials for hightemperature applications. Encouraging results in the areas of polymer-derived $\mathrm{SiC}$ fibers and single-crystal oxide filaments were presented, suggesting that composites with improved thermomechanical properties and stability will be realized in the near future.

A significant number of the presentations about matrices dealt with reduction or displacement reactions, also known as "thermite" reactions. Controlled chemical interactions between two materials, which in the described systems are typically exothermic, are used to form different, more stable "composite" compositions with fascinating microstructures. Interesting combinations of materials were explored, many having great promise for use as composite matrices and/or stand-alone compounds. Continued improvements in the mechanical models, combined with more extensive testing, also supported the fundamental premise for examining continuous fiber ceramic composites; i.e., low modulus ceramic fibers can be added to stiff ceramic matrices to produce materials with good strength, high-temperature performance, and exceptional toughness.

Two days of the symposium were devoted to fiber-matrix interfaces in continuous fiber-reinforced ceramic matrix composites. The talks were separated into four sessions: mechanical modeling, test methods, interface behavior, and modification and control. The significance of the fiber-matrix interface in the design and performance of these materials is evident. Numerous mechanical models to relate interface properties to composite behavior, and interpret test methods and data, were enthusiastically discussed. Issues such as residual stresses, load transfer, fiber roughness, fiber coatings, and environmental stability were noted. Improved test methods and data analysis have provided more accurate and detailed information about the forces acting at this boundary and have enhanced the understanding of fiber debonding and sliding. A variety of new coating systems for improved performance and stability are being developed with some interesting new developments in interlayers for oxide-oxide composites. 
The issue of stability arose frequently throughout the symposium. Corrosion, thermal shock resistance, and cyclic thermomechanical loading were primary concerns for limiting the life of ceramic composites in many of the potential applications.

Symposium Support: Air Force Office of Scientific Research, NASA Lewis Research Center, ORNL.

\section{Questions Posed Concerning Dynamics in Small Confining Systems (See MRS Proceedings Volume 366)}

Symposium N, the third MRS Fall symposium on Dynamics in Small Confining Systems, touched on a wide range of topics on static and dynamic properties of small confining systems: probing of confined systems, structure and dynamics of liquids at interfaces, nanorheology, adsorption, diffusion in pores, and reactions. More than 100 presentations from various disciplines shared different points of view on the questions of how ultrasmall geometries can force a system to behave in ways significantly different from its behavior in the bulk, how this difference affects molecular properties, and how it is probed.

Of special interest was the session on nanorheology, where new experiments and theoretical approaches were discussed. The possibility was raised that sheared liquids between nearby surfaces may, in the sliding state, display processes on many scales. Fourier transforms of the system's response to an external drive have revealed fluctuations over all accessible frequencies. The underlying mechanism for this hierarchical behavior is still not known. New analytical and numerical (molecular dynamics) results have been introduced proposing frameworks for understanding sheet thinning, structuring of liquids at interfaces, and phase transitions under confinement. Clearly, in spite of the new experimental and theoretical investigations, a microscopic-level understanding of the frictional properties of confined liquids is still missing. The need for new approaches has been recognized and the possibility of introducing optical probes as sensors of local dynamics was mentioned.

Other sessions dealt with various ways to probe the nature of liquids near interfaces. Notable among these methods are $x$-ray reflectivity and grazing incidence diffraction experiments, $x$-ray surface forces apparatus, light scattering, NMR, and dielectric relaxation. Liquid crystals have proven interesting in the investigations of the role of confinements on ordering and phase transitions.

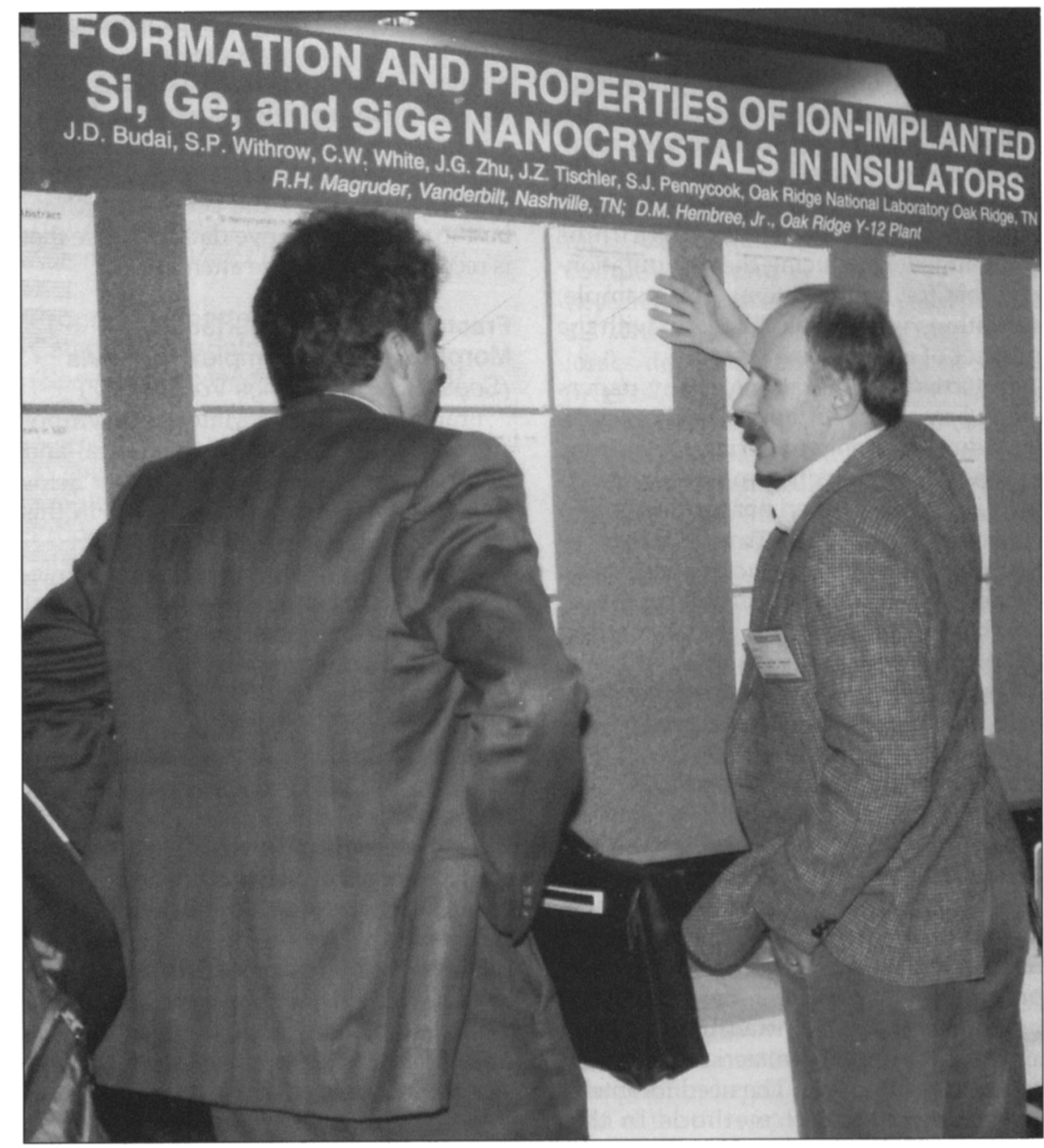

Researchers discuss nanocrystals in insulators at a poster presentation.

A new mechanism for molecular diffusion at solid-liquid interfaces was proposed. Theoretically, under certain conditions, large steps are executed by desorbed molecules that move through the liquid from one surface site to another. Motion dominated by such steps does not follow the usual Brownian rules but rather obeys different statistics-those of Levy walks. A similar mechanism was invoked in an experimental presentation on molecular diffusion in porous glasses using field-gradient NMR.

Recent advances in diffusion-reaction dynamics were covered. Modifications to include reactions in small volumes such as micelles have been introduced using stochastic approaches. The theory has been successfully applied to analyze experiments and it has been demonstrated that one can determine the size of micelles by analyzing quenching reactions.

Symposium Support: Exxon Research and Engineering Co., ONR.

\section{Advances Made Toward the Prediction of Properties of Complex Materials}

Computational approaches for predicting the properties of materials are becoming progressively more powerful. This progress is driven by the wider availability of novel computational architectures, as well as by significant advances in algorithms. Symposium Oa, Computational Approaches and Applications to Predicting the Properties of Complex Materials, focused on approaches which predict properties of complex materials, on new computational techniques, and on work which has significantly extended the understanding of a diverse range of physi- 
cal properties and processes.

Novel algorithms for solving the Schrödinger equation were discussed. Some of these algorithms were targeted at taking advantage of new computer architectures, e.g., algorithms were designed to take optimal advantage of massively parallel computers. Other algorithms were aimed at reducing the computational effort for large systems, for example, algorithms which scaled linearly with the number of atoms in the system.

In terms of applications, many papers were presented on complex materials, including photonic materials, fullerenes, oxides, thermoelectric materials, polymers, hydrides, superhard materials, ferroelectrics, dielectrics, ferromagnets, hightemperature superconductors, electronic materials, and intermetallic alloys. Much emphasis was placed on understanding the properties of materials in terms of the influence of interfaces, extended and point defects, and grain boundaries.

\section{Innovative Computer Methods Foster Materials Designs}

Symposium Ob, Applications of Innovative Knowledge Bases in Materials Design, comprised mostly invited talks focusing on the uses of computers in improving or conducting the design process. N.P. Suh (MIT) opened with a presentation on a nontraditional design approach that covers materials from concept through product. The need for intelligent computational methods in this process was discussed by Y-H. Pao (Case Western Reserve Univ.). How to integrate atomic through macroscale information about materials was presented by S. Iwata (Univ. of Tokyo). Predictive approaches included a system developed by $\mathrm{N}$. Kiselyova (Baikov Inst.), a knowledge base created by A.G. Jackson (Wright Patterson AFB), and a polymer knowledge base developed by J. McDowell (MI State Univ.). With these basics in hand, several researchers revealed applications of databases and knowledge bases to materials design and improvements in properties. The broad range of materials types included thermoplastics, powders, semiconductors, polymer composites, and an adaptive thermal spray process.

The trend emerging from this symposium is that inexpensive computer capability has progressed to the point where practical, real-time, self-adaptive systems will be available in the next few years. Research into the properties of materials and the search for new materials will benefit markedly from these advances because the data and knowledge that currently exist will be available for automated pro- cessing. With the budget crunch becoming more intense, materials designers, materials researchers, and materials users will find that they are relying more and more on computer-based knowledge systems to process data and knowledge. This set of papers exemplifies the problem of how best to use and improve data, an issue that is receiving worldwide attention.

\section{Fractals Applied to Surface Morphology and Complex Materials (See MRS Proceedings Volume 367)}

Fractal Aspects of Materials, Symposium $P$, brought together theoretical and experimental experts from different fields to lay out the latest developments in this area.

A highly important application of fractals in materials science is in the area of surface and interface science. In this session, growth of thin films by atomic beam deposition and electrochemical techniques were discussed. Fractal and dynamical scaling concepts were used to describe the observed morphologies of the islands as well as the temporal evolution of the island size distribution in $\mathrm{MBE}$. The critical island size was found to be an important parameter controlling submonolayer growth

Kinetic Roughening in Thin-Film and Epitaxial Growth, a joint session with Symposia B1 and D, attracted the largest number of attendees in a regular scientific session at this meeting and included an invited talk by 1994 MRS Medalist M. Lagally. This session focused on the mechanisms that control the evolution, morphology, and, in particular, the kinetic roughening of surfaces in epitaxial growth. A key factor in surface roughening is the so-called Schowebel barrier to diffusion of atoms down a step. This leads to an instability which causes the formation of mounds with an angle of a few degrees and, subsequently, to surface roughening. Lagally spoke on his recent find, the anomalous effects of temperature on diffusivity on semiconductor surfaces, a puzzling result that contradicts current understanding of thermal effects on surface morphology

The role of percolation theory in understanding disordered materials and modeling porous media was discussed in another session. Researchers introduced a novel model of glassy materials based on frustrated percolation ideas, which produced excellent ageements with both the static properties and the dynamical relaxation of glassy materials. Novel experimental techniques such as x-ray scattering, spin echo, and nuclear relaxation experiments were discussed and their use in effectively determining the fractal pore size distribution in porous media was shown.

The study of complex materials, from aggregation to colloidal particles to the growth and formation of polymers and biological materials, has been a highly active area in the application of fractal and scaling ideas. Contributions in this session focused on morphological and fractal properties of biological materials, as well as on polymers. A topic of ongoing activity is the kinetics of aggregation of colloidal particles. Some new results were presented using a novel approach for scaling the structure function in colloidal aggregation under different growth conditions.

The other general topics elucidated during this four-day symposium included diffusive instability in materials growth, fractal aspects in the fracture and breakdown of materials, the slow relaxation of glass materials, and the problems of granular materials.

Symposium Support: ONR.

\section{Researchers Focus on Defects in Ordered Polymers}

Symposium Q, Characterization and Properties of Defects in Polymer Materials, concentrated on the theory, simulation, characterization, and properties of defects in ordered polymer materials. Defects in ordered polymers include chain ends, chain folds, chain twists, dislocation, disclinations, grain boundaries, and surfaces. The influence of these defects on macroscopic properties and the ability to control the number and type of the defects present is a topic of continuing interest in polymer materials science. This symposium featured four areas: (1) overview, theory, and simulations; (2) deformation and grain boundaries, (3) liquid crystals and liquid crystal polymers, and (4) block copolymers and surfaces.

Symposium Support: Air Force Office of Scientific Research.

\section{Rational Molecular Design Reiterated Throughout Polymer Matrix Composites Symposium}

Symposium R, Polymer Matrix Composites, contained several principal areas, including new or modified matrix materials, novel nanocomposites, tailored interfaces, fracture and degradation processes, new processing techniques, and new instrumental techniques for sensitively monitoring physical and chemical processes that occur in composites. Rational molecular design of matrices, nanocomposites, and interfaces was a recurring theme. The body of knowledge, as well as recent advances, in the area of molecular synthe- 
sis and properties was used to create new or improved materials to meet specific applications.

Much progress was reported in the adaptation and miniaturization of instrumental analysis techniques for the investigation of composite microstructure and submicrostructure, as well as of curing and performance. This has allowed some physical, mechanical, and chemical processes to be monitored-for the first time-as they occur in situ, and is providing long-needed clarification and understanding of processing, damage accumu lation, and performance.

Symposium Support: Air Force Office of Scientific Research.

\section{Area of Mineralization Emphasized in Biomaterials}

Symposium S, Biomolecular and Biomimetic Materials, covered a series of topics, including biomineralization, thin-film formation, and biopolymers. In the area of mineralization, the focus was on structures and mechanisms. Mineralized tissues display very elegant structures; a first reflex is to attribute these to close control of nucleation and growth by some omnipotent cellular mechanism, although the cause is probably not that complicated. A number of papers demonstrated control of mineralization of synthetic surfaces and showed apparently biogenic crystals growing from solutions containing biological or synthetic polymers.

One long-term goal of the mineralization studies is to develop an understanding sufficient to allow us to make synthetic devices from shaped and patterned crystals grown under ambient conditions. In the thin-film section, much of the work dealt with the use of lipids as templates for the deposition of metals, semiconductors, proteins, and active organics. A less elegant alternative to modification of a Langmuir-Blodgett film is to incorporate the active species into a sol-gel matrix. These robust, transparent films seem ideal for optical sensors. These developments can be seen as forming the basis for a new technology, whose exact form is still unclear.

In past years, the polymer section has been concerned with the formation and manipulation of biological polymers, especially silks. This year's sessions focused more on the interface between research and development of biological polymers. In addition to silk, papers discussed such polymers as microbial copolyesters, microbial cellulose, and a new commercial cellulose fiber. Liquid crystallinity is common in solutions of biological polymers. Since liquid crys- talline solutions orient readily during spinning, and highly oriented fibers have a high modulus, this has interesting implications for fiber properties.

Symposium Support: Alpha-Beta Technology, ARO, Courtaulds Strategic Research \& Technology, Dow Chemical Co. - Central Research Dow Chemical Co.-Ventures, ONR, Sandia National Labs., Vertex Pharmaceuticals Inc.

\section{Progress Reported in New \\ Catalytic Materials}

(See MRS Proceedings Volume 368)

Catalysts form the heart of many oil and petrochemical processes, and are helpful in solving or preventing environmental problems. Symposium T, Synthesis and Properties of Advanced Catalytic Materials, dealt with progress being made in new catalytic materials.

Most catalysts are based on metals and/or oxides, but a developing area is concerned with nitrides and carbides. Significant results were reported by M.J. Ledoux (Univ. of Louis Pasteur) on an $\mathrm{Mo} / \mathrm{C} / \mathrm{O}$ phase that shows superior performance to commercially applied $\mathrm{Pt} /$ zeolite catalysts in the isomerization of alkanes, a reaction of importance in gasoline manufacture.

In addition to composition, catalyst shape and porosity are important parameters. New materials in these respects are perovskite honeycombs and ceramic foam-based catalysts, useful in the total or partial combustion of methane (V.A. Sadykov, Boreskov Inst. of Catalysis, and L.D. Schmidt, Univ. of MN).

Progress in the field of supported molecular complexes was illustrated by the finding that high chiral selectivity could be obtained in an elegant catalytic system that consists of a water-soluble chiral Ru phosphone catalyst dissolved in an aqueous layer supported on a porous glass in contact with a second, organic liquid layer containing reactants and products (M.E. Davis, CIT). Chiral catalysis can be of major importance in the synthesis of drugs.

Symposium Support: Air Products \& Chemicals Inc., Catalytica, DSM Research, DYCAT International, Exxon Research and Engineering, General Motor Corp., Haldor Topsoe AVS, MEL Chemicals, Mobil Corp., Shell Oil, Union Carbide, W.R. Grace.

\section{New Frontiers Explored in Solid State lonics}

\section{(See MRS Proceeding Volume 369)}

The fifth symposium on Solid State Ionics, Symposium U, comprised more than 152 papers from 17 countries and had more than double the attendance of the previous event in 1992. The field of solid state ionics enjoys a significant activity due to several accomplishments in the areas of solid state batteries, supercapacitors, sensors, catalysis, and electrochromic devices. The symposium addressed areas such as insertion compounds, sol-gel process, theory of ion conduction in condensed matter, materials for batteries and supercapacitors, ionic and electronic polymers, carbon and graphite intercalation compounds, and ceramic electrolytes. Researchers presented many new materials with desired properties for various ionics devices. New prospects in sol-gel process and preparation of nontraditional ceramics and organic-inorganic composites were discussed. Other topics included new polymer and rubbery electrolytes for battery applications, new phenomena, novel characterization techniques, frontiers in theory of ion transport in condensed matter, and real-time computer simulation of large systems. The symposium represented the frontier in applied solid-state chemistry, electrochemistry, and materials aspects of ionics.

Symposium Support: Bellcore, Lawrence Berkeley Lab., M. Braun Inc., ONR.

\section{Microstructure of Prehistoric to Specialty Cements Broadly Covered (See MRS Proceedings Volume 370)}

Symposium Va, Microstructure of Cement-Based Systems, covered a wide variety of techniques and applications of microstructural investigation for a broad range of cement-based materials. The symposium began with a unique exposition of the microstructures of relics of prehistorical and historical cements and concretes. Direct evaluation of current microstructures, employing mostly backscatter SEM and quantifying features by image analysis, was a major component of the presentations. Pore structures and cracks induced by loading were prominent among the special features investigated.

Pixel-based computer modeling of cement microstructures received some attention, and an innovative set of linked three-dimensional models at three different levels of scale was introduced.

Applications of unusual microscopic techniques to fundamental problems and to practical field control of concrete were disclosed, with methods including confocal microscopy, fluorescent microscopy, and $\mathrm{x}$-ray microtomography. Significant contributions to the development of indirect methods for exploring microstructural aspects of various specialized cementbased systems were detailed, including radioactive waste forms, coal combustion by-products, and cement systems incorporating various industrial wastes.

The special microstructural characteristics of interfacial transition zones devel- 
oped between hardened cement pastes and various inclusions including sand, crushed rock, and fibers were explored in a joint session with Symposium Vb, Bonding and Interfaces in Cementitious Materials.

Symposium Support: Portland Cement Assoc.

\section{Cement Interfaces Elicit Lively Discussions}

(See MRS Proceedings Volume 370)

Modern high-performance concretes are increasingly model as three-phase materials consisting of hardened cement paste, aggregate, and the interfacial transition zone (ITZ) between the bulk paste and the aggregate. In ordinary concretes, the ITZ has been the "weak link." For high-performance concretes, however, the properties of the ITZ have become increasingly important, not only in terms of strength, but also in terms of the transport properties (permeability) of the composite material. Symposium $\mathrm{Vb}$, Bonding and Interfaces in Cementitious Materials, explored in detail the problems of determining the properties of the ITZ, and the effects these properties might have on the composite properties. The two-day symposium included 36 papers, half of which were contributed from outside the U.S. Major topics included microstructure characterization of the ITZ, mechanical and fracture properties of the ITZ, transport properties, and fiber/matrix interaction.

The papers and lively discussions still demonstrate no agreement on how best to characterize either the microstructure or the mechanical properties of the ITZ. Similarly, isolating the effects of the ITZ on the concrete properties remains difficult. Nonetheless, we appear increasingly able to modify the properties of the ITZat least empirically- to improve concrete properties. Further work should ease the process to "tailor-make" concretes for particular applications by further modifying both the cementitious matrix and the ITZ.

Symposium Support: Portland Cement Assoc.

\section{Advances in Porous Materials Lead to Better Materials for Catalysis, Insulation, and More \\ (See MRS Proceedings Volume 371)}

Symposium W1, Advances in Porous Materials, attracted researchers from such diverse disciplines as materials science, chemistry, chemical engineering, and metallurgy. Topics included microporous, mesoporous, and macroporous oxides, metals, and carbon/polymers.

The design and synthesis of porous

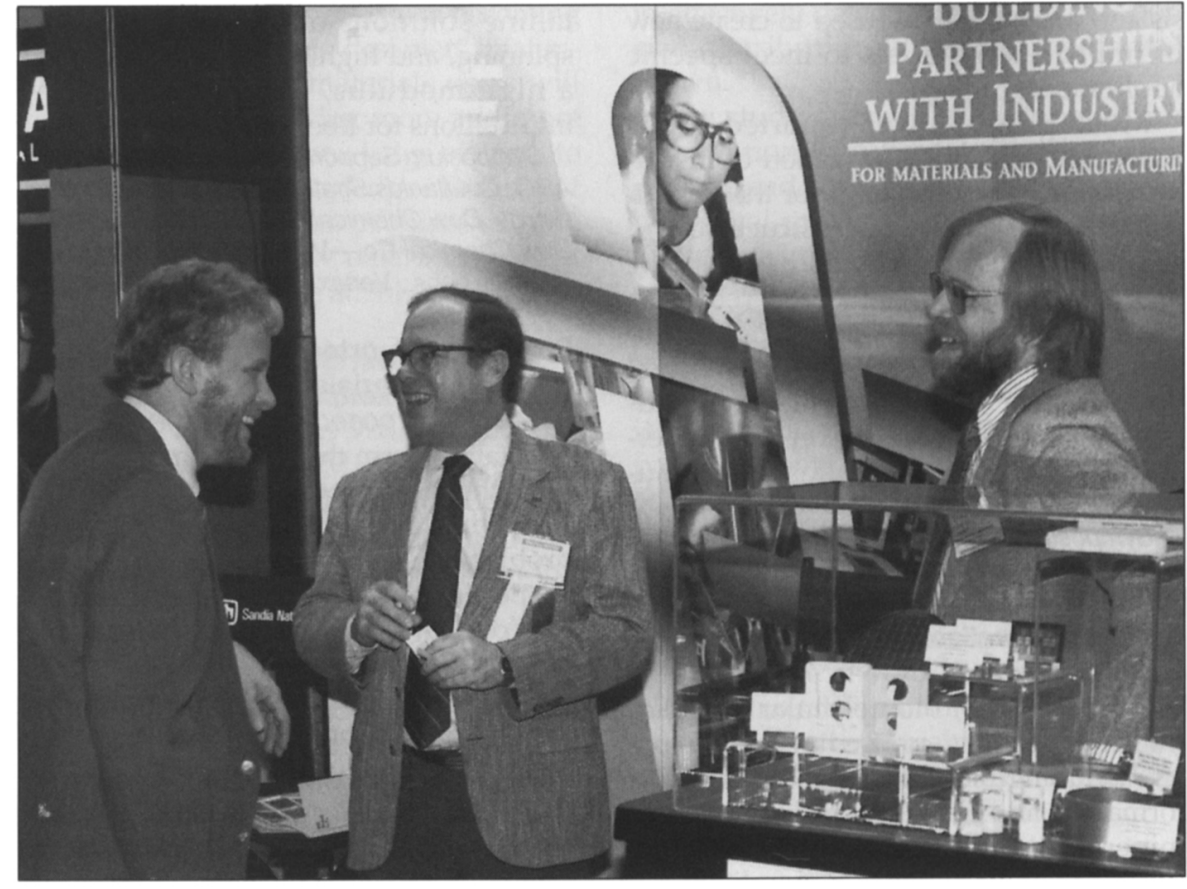

Conference attendee visits one of the many Exhibitors' Booths.

materials is more challenging than the processing of dense materials because brute force methods will not work in the former case. M.E. Davis (CIT) depicted rational strategies for partially designed synthesis of zeolites. S. Yamanaka (Hiroshima Univ.) described new anionexchangeable layered mixed basic salts.

G.D. Stucky (U.C.-Santa Barbara) delineated the mechanism or synthesis of the mesoporous molecular sieves recently developed by Mobil Corp. Several other papers on these new molecular sieves characterized different substitutions and catalytic activities. L.W. Hrubesh and J.F. Poco (Lawrence Livermore National Lab.) and J. Fricke (Univ. Würzburg) illustrated the various applications, including use of aerogels, the lightest solids known, as insulation.

In regards to macroporous materials, E.W. White (Interpore International) and R. Roy (Penn State) described tailored porosity in commercialized ceramics via a biomimetic process, termed replamineform. K. Kaneko (Chiba Univ.) showed that the graphite micropore of subnano order facilitates the $(\mathrm{NO})_{2}$ disproportionation reaction which normally occurs under high pressure.

Several papers described the novel GASAR porous metals, which are produced by a liquid-gas eutectic reaction process that involves gaseous hydrogen; these are expected to be useful as lightweight structural materials.

Symposium Support: Air Products \& Chemicals Inc., ALCOA, Cabot Corp., Gas Research Inst., Lawrence Livermore National Lab., Los Alamos National Labs., Millipore Co. Sandia National Labs.

\section{Still More to Learn about Microstructure of Irradiated Materials (See MRS Proceedings Volume 373)}

Symposium $Y$, Microstructure of Irradiated Materials, addressed the defect production and accompanying microstructural changes that occur in solids during irradiation with energetic particles (e.g. ions, electrons, neutrons, or gamma rays). The 120 papers, judiciously selected from a field of 180 submitted abstracts, drew high attendance.

The first day featured a variety of talks on irradiated metals. New insights into underlying processes of microstructural development emerged from many comparisons of molecular-dynamics calculations with experimental results, primarily electron microscopy observations. Irradiated insulators and ceramics provided the theme for the second day. The once highly disputed topic of radiationinduced electrical degradation (RIED) reemerged as a major focus for the fusion materials community and, in several presentations, in situ high-voltage electron 
microscopy demonstrated its efficacy. The third day consisted of morning sessions on mechanical property changes in fission-reactor materials - a topic of increasing importance as many of the approximately 200 U.S. power reactors achieve operating lifetimes approaching 30 years-and an afternoon devoted to ion implantation in semiconductors in which it quickly became obvious that there is still much to learn, even in the case of implanted Si!

Symposium Support: AEA Technology, E.A. Fischione Instruments Inc., JEOL USA Inc., Materials Research Lab.-Univ. of IL, ORNL.

\section{Successful Devices for Optical Waveguide Materials Generate New Possibilities}

Optical Waveguide Materials, Symposium $\mathrm{Za}$, was the third MRS symposium devoted to the properties and synthesis of materials for optical waveguides. The use of optical fibers as passive transmission media in many areas of technology is already well-established. More recently, the success of the erbium-doped optical fiber amplifier (EDFA) for amplification in the $1.55 \mu \mathrm{m}$ telecommunications window has spawned interest in a host of active fiber and planar waveguide devices. Fiber and waveguide lasers, dispersion compensators, modulators, transmission filters, and second-harmonic generators are only a few examples of potential applications.

In regards to silicon-based photonics, efforts to develop integrated optical devices (including modulators) in SIMOX and pure silicon, as well as in SiGe alloys, were described. Identification of a light source in these systems continues to be an issue, but progress in achieving room temperature emission from Er ions was reported. B. Kurdi (IBM) discussed the use of an antiresonant reflecting optical waveguide (ARROW) structure built on silicon for use in optical data storage.

$S$. Choquette introduced a new application for integrated optics-biochemical sensing. Dispersion compensators, which require high-delta low-loss fiber, and new materials and techniques for planar waveguides were the main subjects in the silica-based session. In the nonsilica session, B. Aitken (Corning) surveyed issues involved in choosing an alternate host for optical amplification in the $1.3 \mu \mathrm{m}$ communications window. Several papers reported progress in developing these hosts.

A separate session was devoted to rareearth (RE) doping for photonics. This brought together researchers adding RE ions to glasses, nonlinear optical crystals, and semiconductors. A report of improve- ments to the properties of the RE dopants by codoping with Ta was particularly intriguing. UV photosensitivity of glass was addressed. The ability to fabricate Bragg gratings in the cores of optical fibers using uv light has generated interest in enhancing the uv photosensitivity of glass via $\mathrm{H}_{2}$ loading or ion implantation, for example.

Nonlinear optical waveguide materials including single-crystal films, metal colloids, and polymers were also discussed. Progress in making single-crystal $\mathrm{BaTiO}_{3}$ films on $\mathrm{MgO}$ on $\mathrm{Si}$ was reported by $\mathrm{R}$. McKee (ORNL). Although difficult materials issues remain to be solved in singlecrystal films and polymers, their high nonlinear coefficients continue to make them attractive for modulators and second harmonic generators.

Symposium Support: AT\&T, Corning inc.

\section{Protection from Laser Radiation Attracts Research on Optical Limiting (See MRS Proceedings Volume 374)}

Materials for Optical Limiting, Symposium $\mathrm{Zb}$, brought together a wide range of scientists involved in research to develop and apply optical materials that can keep laser radiation from reaching delicate optical sensors, including human eyes. The widespread use of lasers in industry and consumer devices necessitates a strong need to protect commonly used optical sensors from intense laser light. Many optical devices could safeguard optical sensors but, due to the lack of a fast-acting, low-threshold optical material, none of the devices offers adequate protection.

Beginning with analytical modeling of optical response, S.J. Till (Defense Research Agy.) described the range of quantum chemical techniques to design new nonlinear optical materials. Several talks covered specific uses of these techniques and what has been achieved over the past few years. T. Chang, (Rockwell Intl. Science Center) then described the development of electrooptic power limiters based on CdTe for infrared applications. Other talks highlighted work on polycarbonate diacetylene and infrared limiters based on $\mathrm{ZnTe}$ and $\mathrm{ZnSe}_{1-x} \mathrm{Te}_{x}$

J. DeNatale's (Rockwell Intl. Science Center) description of his work on $\mathrm{V}_{x} \mathrm{O}_{1 y}$ phase change materials for optical limiting was followed by a series of talks concerning materials that had progressed to the stage where thin-film devices could be fabricated and tested. Several presentations showed that some materials, such as the thiophenes and transition metal clusters, hitherto thought to be opaque, could be fabricated in ways that pro- duced useful materials. G. Salamo (Univ. of $A R$ ) related recent advances in the use of photorefractive materials that make them attractive candidates for limiting in some applications.

Reverse saturable absorbing (RSA) materials are transparent under normal illumination but have large absorption coefficients in the excited state and D. Hagen (Univ. of Central FL) reported on his group's extensive work in this area over the past several years. Several other talks addressed techniques to measure the properties of RSA materials. J. Shirk (NRL) described work by NRL on synthesis and characterization of phthalocyanine limiters.

K. Welford (Defense Research Agy.) described work on organic dyes and on the effects of changes in chemical structure on limiting behavior. Subsequent talks concentrated on the effects of the specific chemical structure of phthalocyanine, porphyrin, and $C_{60}$ on limiting behavior. In addition, the use of very complex transition metal structures (NIDO clusters) and arrays of colloidal particles to limit laser light were described.

I.C. Khoo (Penn State) spoke on optical limiting in liquid crystalline materials. Other talks examined limiting by boron clusters, magnetic liquid-crystalline materials, cubanelike clusters and the design of thin-film devices via a technique used in stored waveform inverse Fourier transform ion cyclotron resonance mass spectrometry.

Symposium Support: Lawrence Assoc. (Wright Patterson AFB).

\section{Synchrotron Radiation Techniques Applied to Materials Science}

\section{(See MRS Proceedings Volume 375)}

The symposium on Applications of Synchrotron Radiation Techniques to Materials Science, Symposium AA, explored such experimental techniques as extended $x$-ray absorption fine structure (EXAFS), synchrotron $x$-ray diffraction and fluorescence microprobe, and soft $x$ ray photoemission. Other talks probed various types of materials systems, ranging from alloys to polymers to single crystals of metals. One talk reported research centering around the study of aluminum silicon, and magnesium materials using EXAFS spectroscopy in the 1-2 keV region, while another study addressed the use of high-energy (100 keV) synchrotron radiation to obtain the structure factors for amorphous solids and to study defect scattering from Czochralski-grown silicon crystals. Other presentations detailed photoemission studies relating to the investigation of the chemistry and physics of 
fullerenes, emphasizing the fullerenes' narrow band character, the role of vibronic coupling, and the importance of band dispersion.

Symposium Support: ANL, Blake Industries, Lawrence Berkeley National Lab., Lawrence Livermore National Lab., ORNL.

\section{Neutron Scattering in Materials Science Matures}

(See MRS Proceedings Volume 376)

Neutron Scattering in Materials Science, Symposium BB, drew a large and international group of participants: 21 nations were represented among the presenters at 13 sessions.

On the basis of both the results described and a high attendance, neutron reflectivity has clearly undergone marked growth and maturation. The measurements derived from neutron reflectivity provide an exquisite probe of the structure of surfaces and interfaces, be these buried within a solid or at a solid/solution interface. The power of the method derives from the large penetration depth of neutrons and the difference in scattering length between isotopes-for example, in the case of the proton and deuteron. A number of studies capitalized on the latter feature to examine phase separation of polymers and the structure of confined diblock copolymers. Scattering contrast was also the basis of results reported from small-angle neutron scattering (SANS) measurements obtained from materials as diverse as polymers, micelles, and microemulsions, as well as inorganic gels composite materials, and ceramics. Further applications of SANS appeared in a session specifically devoted to cementitious materials.

Symposium Support: ANL, Federal Highway Adm., NIST, Neutron Scattering Soc. of America (c/o IA State Univ.).

\begin{tabular}{|c|c|}
\hline \multicolumn{2}{|c|}{ Advertisers in This Issue } \\
\hline${ }^{\star}$ Digital Instruments & \\
\hline Elchema & 73 \\
\hline `Elsevier Science & 72,74 \\
\hline $\begin{array}{l}{ }^{*} \text { Fisons Instruments } \\
\text { Surface Systems }\end{array}$ & 19 \\
\hline $\begin{array}{l}\text { *High Voltage } \\
\text { Engineering Europa inside fron }\end{array}$ & it cover \\
\hline *Huntington Laboratories & k cover \\
\hline *JEOL U.S.A., Inc. & 22 \\
\hline Kipp \& Zonen & 18 \\
\hline `Kurt J. Lesker Co. & 23 \\
\hline Linn High Therm & 70 \\
\hline $\begin{array}{l}\text { *Magnet Sales and } \\
\text { Manufacturing Inc. }\end{array}$ & 15 \\
\hline *MDC Vacuum Products Corp. & 6 \\
\hline MKS Instruments, Inc. & 12 \\
\hline *n\&k Technology, Inc. & 70 \\
\hline Nanophase Technologies Corp. & 18 \\
\hline *National Electrostatics Corp. & 28 \\
\hline *New Focus, Inc. & k cover \\
\hline Oxford University Press & 69 \\
\hline “Philips Analytical X-Ray & 5 \\
\hline “Plasma Science Inc. & 13 \\
\hline Princeton Gamma Tech & 14 \\
\hline Quantum Design & 16 \\
\hline Semiconductor Processing Co. & 31 \\
\hline $\begin{array}{l}\text { "Siemens Analytical } \\
\text { X-Ray Instruments }\end{array}$ & 21 \\
\hline${ }^{*}$ Staib Instrumente & 9,17 \\
\hline University of California, Berkeley & 36 \\
\hline${ }^{*}$ Virginia Semiconductor & 10 \\
\hline *VLSI Standards Inc. & 24 \\
\hline "Voltaix, Inc. & 28 \\
\hline *Wyko Corp. & 11 \\
\hline $\begin{array}{l}\text { For free information about the products and } \\
\text { vices offered in this issue, fill out and mail th } \\
\text { Reader Service Card, or fax it to (312) } 922-3\end{array}$ & \\
\hline $\begin{array}{l}\text { “Please visit us at the Exhibit, April 18-20, du } \\
\text { the } 1995 \text { MRS Spring Meeting in San Francis } \\
\text { For a complete list of exhibitors, please see }\end{array}$ & $\begin{array}{l}\text { ring } \\
\text { sco. } \\
\text { sage } 65 .\end{array}$ \\
\hline
\end{tabular}

\section{Neutron Researchers Honor One of Their Own}

The annual meeting of the Neutron Scattering Society of America took place as part of Symposium BB, Neutron Scattering in Materials Science. Attendees honored longtime member Cliff G. Shull (MIT), co-recipient of the 1994 Nobel Prize in Physics for his pioneering efforts in neutron diffraction, with several minutes' ovation. Shull spoke briefly about his early research at Oak Ridge National Laboratory on crystal diffraction of neutron beams, saying that he and coworker Ernie Wallen had studied many months simply to recognize and accept the finding that neutron scattering intensities were the same no matter which compound served as the diffraction medium.

The remainder of the meeting, intended in part for prospective users of neutron scattering, featured descriptions and procedures for accessing the instrumentation at seven major neutron sources in North America. The representatives described their reactors' architecture and capabilities and provided contact information for prospective users. Each representative also warned, however, that experimental time and financial support for outside scientists is extremely limited at these facilities.

The facilities described were Brookhaven National Laboratory's HFBR, Oak Ridge's HFIR, the National Institute of Standards and Technology's NBSR, the Missouri University Research Reactor (MURR), Argonne National Laboratory's IPNS, Los Alamos National Laboratory's LANSC, and the Canadian Institute for Neutron Scattering's NRU at Chalk River, Ontario.

\section{AD CLOSING DEADLINES}

April 3, 1995 for the May Issue

Theme: In Situ: Real-Time

Characterization of

Film Growth Processes

May 1, 1995 for the June Issue Theme: Organic Thin Films

TO PLACE YOUR AD, CALL MARY E. KAUFOLD TODAY! (412) 367-3036
SPECIAL OFFER!

\section{BUY 2 ADVERTISEMENTS, GET I FREE!}

Purchase one ad each in the Journal of Materials Research and in the 1995 MRS Membership

Directory and receive a FREE ad in the MRS Bulletin.

$$
\begin{gathered}
\text { Call Mary E. Kaufold at } \\
412 / 367-3036 .
\end{gathered}
$$
70

For free information about the products and services offered in this issue, fill out and mail the

'Please visit us at the Exhibit, April 18-20, during For a complete list of exhibitors, please see page 65 . 